\title{
Searching for single domain magnetite in the "pseudo-single-domain" sedimentary haystack: Implications of biogenic magnetite preservation for sediment magnetism and relative paleointensity determinations
}

\author{
Andrew P. Roberts, ${ }^{1,2}$ Liao Chang, ${ }^{1,3}$ David Heslop, ${ }^{2}$ Fabio Florindo, ${ }^{4}$ \\ and Juan C. Larrasoaña ${ }^{2,5}$ \\ Received 30 April 2012; revised 5 July 2012; accepted 10 July 2012; published 22 August 2012.
}

[1] Magnetic hysteresis measurements of sediments have resulted in widespread reporting of "pseudo-single-domain"-like magnetic properties. In contrast, the ideal single domain (SD) properties that would be expected to be responsible for high quality paleomagnetic records are rare. Determining whether SD particles are rare or common in sediments requires application of techniques that enable discrimination among different magnetic components in a sediment. We apply a range of such techniques and find that SD particles are much more common than has been reported in the literature and that magnetite magnetofossils (the inorganic remains of magnetotactic bacteria) are widely preserved at depth in a range of sediment types, including biogenic pelagic carbonates, lacustrine and marine clays, and possibly even in glaci-marine sediments. Thus, instead of being rarely preserved in the geological record, we find that magnetofossils are widespread. This observation has important implications for our understanding of how sediments become magnetized and highlights the need to develop a more robust basis for understanding how biogenic magnetite contributes to the magnetization of sediments. Magnetofossils also have grain sizes that are substantially smaller than the $1-15 \mu \mathrm{m}$ size range for which there is reasonable empirical support for relative paleointensity studies. The different magnetic response of coexisting fine biogenic and coarser lithogenic particles is likely to complicate relative paleointensity studies. This issue needs much closer attention. Despite the fact that sediments have been subjected to paleomagnetic investigation for over 60 years, much remains to be understood about how they become magnetized.

Citation: Roberts, A. P., L. Chang, D. Heslop, F. Florindo, and J. C. Larrasoaña (2012), Searching for single domain magnetite in the "pseudo-single-domain" sedimentary haystack: Implications of biogenic magnetite preservation for sediment magnetism and relative paleointensity determinations, J. Geophys. Res., 117, B08104, doi:10.1029/2012JB009412.

\section{Introduction}

[2] Development of the alternating gradient magnetometer (AGM) [Flanders, 1988] and electronic improvements that enabled more rapid and sensitive magnetic measurements using well-established vibrating sample magnetometer

\footnotetext{
${ }^{1}$ National Oceanography Centre, University of Southampton, Southampton, UK.

${ }^{2}$ Research School of Earth Sciences, Australian National University, Canberra, ACT, Australia.

${ }^{3}$ Now at Paleomagnetic Laboratory 'Fort Hoofddijk', Department of Earth Sciences, University of Utrecht, Utrecht, Netherlands.

${ }^{4}$ Istituto Nazionale di Geofisica e Vulcanologia, Rome, Italy.

${ }^{5}$ Area de Cambio Global, Instituto Geológico y Minero de España, Oficina de Proyectos de Zaragoza, Zaragoza, Spain.

Corresponding author: A. P. Roberts, Research School of Earth Sciences, Australian National University, Canberra, ACT 0200, Australia. (andrew.roberts@anu.edu.au)

Published in 2012 by the American Geophysical Union.
}

(VSM) technology have facilitated routine measurement of magnetic hysteresis properties in paleomagnetism, rock magnetism and environmental magnetism over the last 20 years. Hysteresis measurements provide an excellent means of detecting grain-size dependent variations in magnetic minerals. Magnetite, as the most common terrestrial magnetic mineral, is expected to be present in a wide range of environments. The grain size of magnetite is an important determinant of paleomagnetic recording fidelity and it can also reflect a range of processes of interest in environmental magnetic studies. Magnetic hysteresis measurements are therefore routinely compared with the grain size dependent hysteresis properties of (titano-) magnetite [Day et al., 1977] to constrain paleomagnetic and environmental magnetic interpretations. As magnetite grain size increases, the efficiency and stability of magnetic recording decreases, as indicated by decreases in two key hysteresis parameters: the coercive force $\left(B_{c}\right)$ and the saturation remanent magnetization $\left(M_{r}\right)$. Other hysteresis parameters are either insensitive (i.e., the saturation 


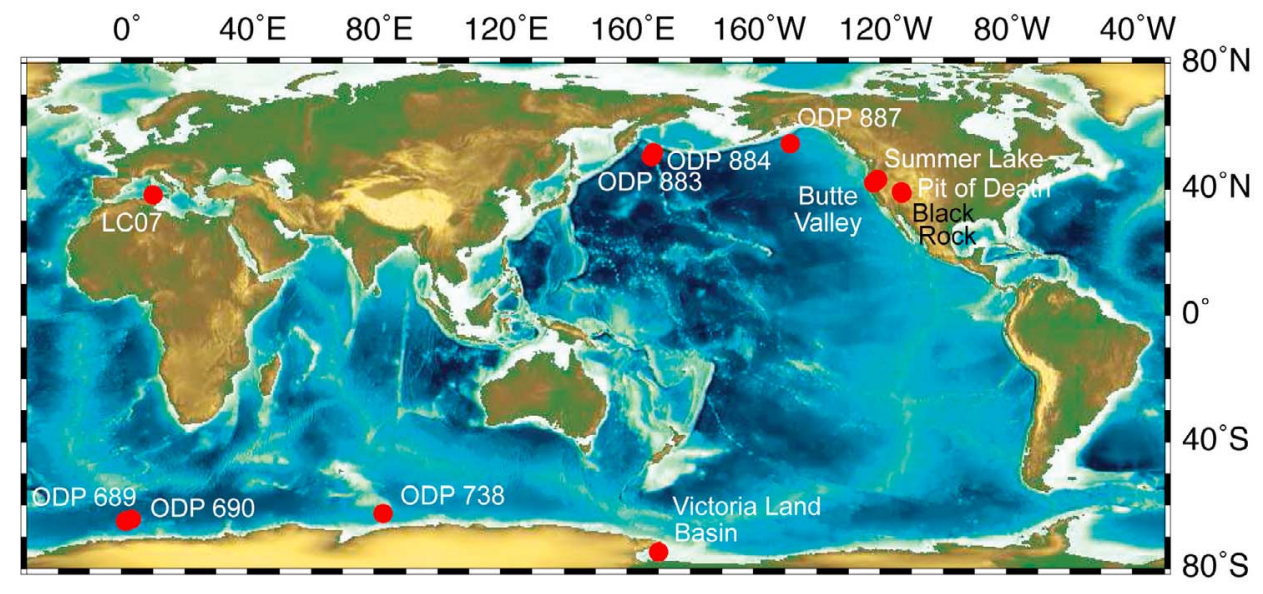

Figure 1. Map with locations of sites from which data are presented in this paper. For details of locations, see site descriptions and cited references in Section 4.

magnetization, $M_{s}$ ) or are less sensitive (i.e., coercivity of remanence, $B_{c r}$ ) to grain size variations. Plots of variations in hysteresis data, with $M_{r} / M_{s}$ plotted versus $B_{c r} / B_{c}$ [Day et al., 1977], have therefore become routine accompaniments to published papers in which magnetite grain size is important. As increasing numbers of so-called 'Day plots' were published since the early 1990s, it became evident that results for most sediments fall in the 'pseudo-single domain' (PSD) field of these plots. Examples involving $>3,000$ samples from globally distributed marine and lacustrine sedimentary environments (Figure 1), in which magnetite is the dominant magnetic mineral, that have been studied by the lead author and colleagues since the early 1990s are shown to demonstrate this point in Figures 2 and 3.

[3] The dominance of 'PSD'-like magnetite in sediments is simultaneously unsurprising and puzzling. On the one hand, the bulk grain size of fine-grained sediments (clays and silts) from many environments encompasses the broad $\sim 100 \mathrm{~nm}$ to several micron size range for PSD magnetite [e.g., Sun et al., 2002; Weltje and Prins, 2003; Sun et al., 2006], so it is to be expected that PSD magnetite grains will occur widely within sediments. Furthermore, the grain size range for ideal single domain (SD) magnetic behavior in magnetite is narrow and fine-grained (i.e., $\sim 30$ to $\sim 100 \mathrm{~nm}$ for equant grains [Dunlop and Özdemir, 1997; Muxworthy and Williams, 2009]) compared to the grain size distribution of most sediments. These observations mean that it should not be surprising that sediments are dominated by 'PSD' rather than by SD magnetite (although the presence of SD grains in source rocks can result in deposition of SD particles within a sediment regardless of the bulk grain size of the sediment). On the other hand, the success of paleomagnetism in contributing to a wide range of problems in Earth science results from the fact that SD grains represent ideal, thermally stable material that can retain remanent magnetizations at ambient temperatures for durations spanning the age of the Earth [cf. Néel, 1955]. It is widely expected that the stable magnetizations documented in paleomagnetic studies ought to be due to the presence of SD particles. Where, then, are these magnetically ideal SD grains in magnetite-bearing clays and silts? Are these grains geologically widespread or are the magnetic properties of sediments really dominated by PSD magnetite? Or do 'PSD'-like magnetic properties represent mixtures of SD and multidomain (MD) end-members [e.g., Dunlop, 2002]? Or are magnetostatic interactions and/or thermal fluctuations sufficiently widespread that $M_{r}$ and/or $B_{c}$ values are reduced to produce bulk PSD-like hysteresis values? These possibilities are all well documented [e.g., Roberts et al., 2000; Muxworthy et al., 2003].

[4] In this study, we address the question of whether SD magnetite grains are rare, like needles in haystacks, or whether they are widespread in sediments. We use techniques that are well suited to identifying SD magnetite within mixed magnetic particle assemblages. The above-described ambiguities inherent to the much-maligned Day plot are well known, but the Day plot is unlikely to become extinct in the near future. In this paper, we provide empirical 'groundtruthing' to assist interpretation of hysteresis data for a range of sedimentary environments to address the questions posed above. In a pair of other papers, Heslop and Roberts [2012a, 2012b] describe numerical approaches to 'unmix' hysteresis data for binary and multicomponent mixtures, respectively. The ground-truthing provided here is important to constrain such numerical unmixing procedures.

\section{Sources of SD Particles in Sediments}

[5] There are multiple potential sources of SD magnetite particles in the studied sediments, including detrital, biogenic and authigenic sources. We consider these possible sources of fine magnetite particles before attempting to interpret hysteresis data from the different sediment types represented in Figures 2 and 3.

\subsection{Authigenic SD Particles}

[6] Genuinely SD-like hysteresis properties are so rare in analyses of bulk sediment samples (cf. Figures 2 and 3) that when $\mathrm{M}_{\mathrm{r}} / \mathrm{M}_{\mathrm{s}}$ values $>0.5$ and $\mathrm{B}_{\mathrm{cr}} / \mathrm{B}_{\mathrm{c}}$ values $\sim 1.5$ are observed, the possible presence of authigenic SD particles with magnetocrystalline anisotropy, such as greigite [e.g., Roberts, 1995; Roberts et al., 2011b], should be suspected. SD monoclinic pyrrhotite with similar hysteresis properties can also occur as an authigenic [Weaver et al., 2002; Larrasoaña et al., 2007; 
Biogenic marine sediments
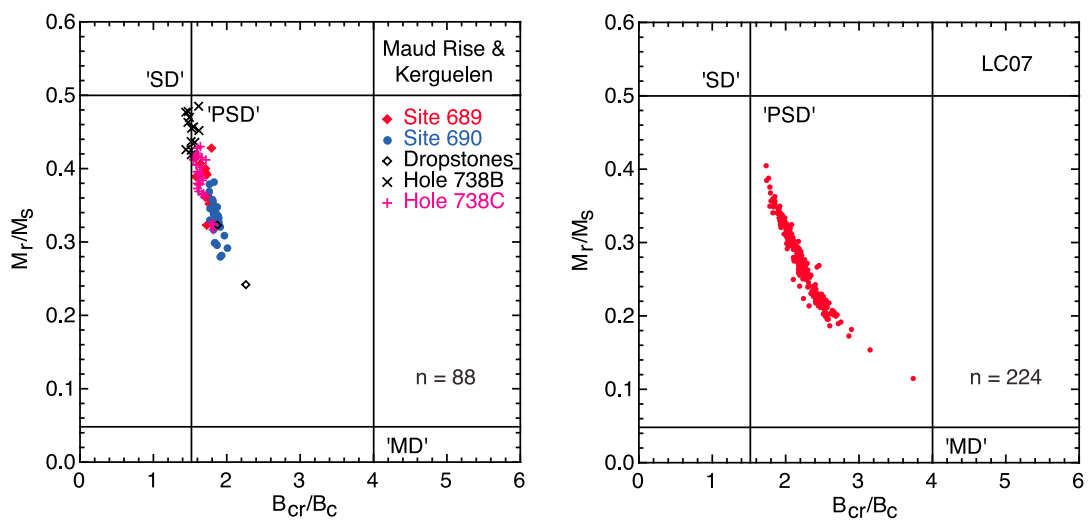

Glaci-marine sediments
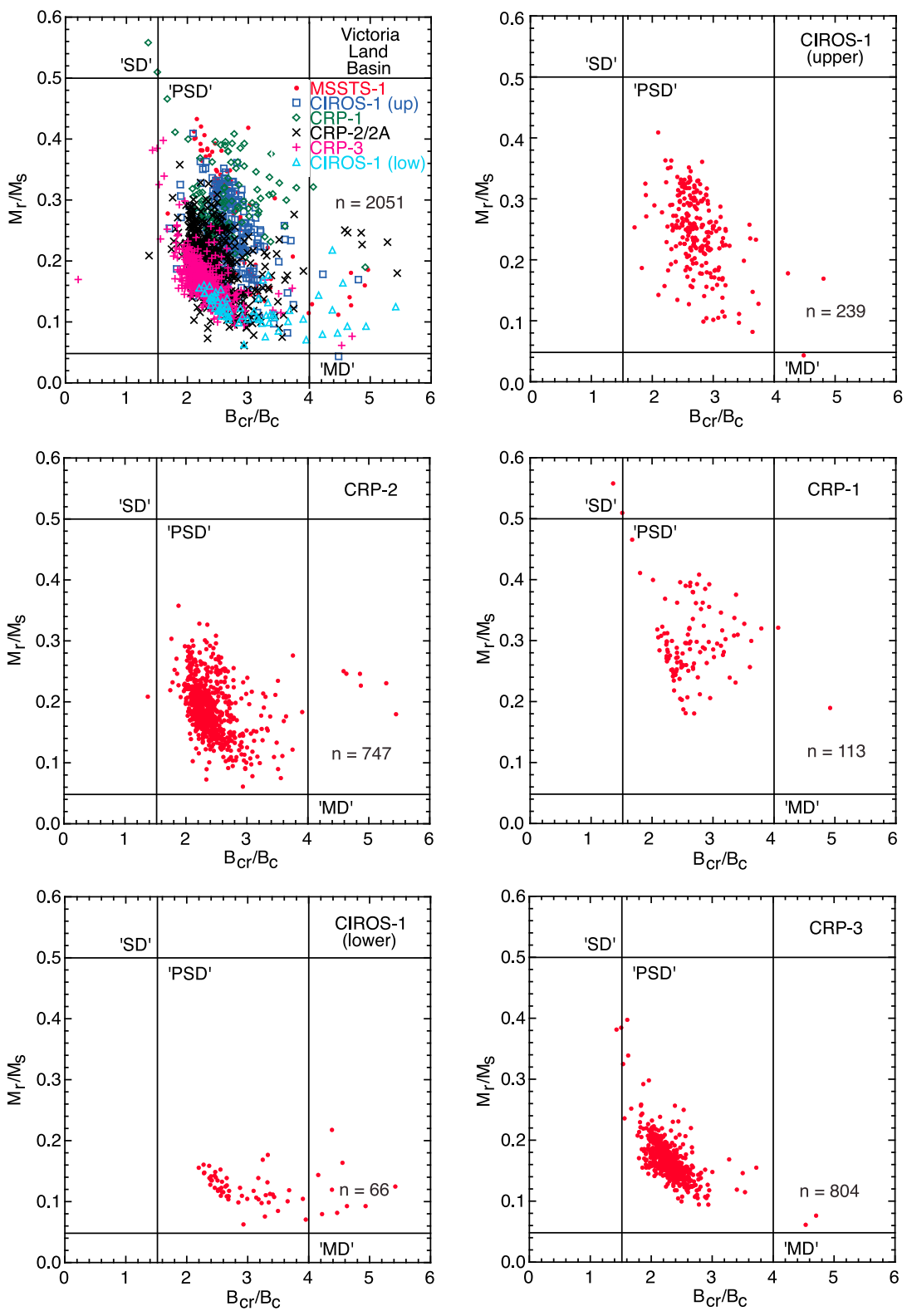

Figure 2 
Roberts et al., 2010] or detrital [Horng and Roberts, 2006] mineral, but sedimentary pyrrhotite is much less common than greigite [Horng and Roberts, 2006]. There are many interesting and important questions concerning magnetic signals carried by sedimentary iron sulfide minerals, but they are outside the scope of this paper. Instead, we focus on the preponderance of magnetite-bearing sediments for which bulk hysteresis parameters fall in the 'PSD' field of Day et al. [1977] (see Figures 2 and 3 ).

[7] Authigenic magnetite can be produced as an extracellular by-product of the activity of non-magnetotactic dissimilatory iron-reducing bacteria [Lovley et al., 1987]. One such species, Geobacter metallireducens (formerly known as GS-15), is an anaerobe that couples organic matter oxidation to reduction of $\mathrm{Fe}^{3+}$, which induces extracellular precipitation of fine-grained magnetite [Lovley, 1991]. Lack of strict biological control on the extracellular crystallization process results in particles that lack unique morphology and that have broad grain size distributions. In the laboratory, this species can produce 5,000 times as much magnetite by weight as an equivalent biomass of magnetotactic bacteria [Lovley, 1991]. Dissimilatory iron-reducing bacteria could therefore be an important source of fine-grained magnetite in sedimentary environments. However, most particles produced by Geobacter metallireducens are superparamagnetic (SP) at room temperature [Moskowitz et al., 1993], therefore, a small proportion of such particles will be paleomagnetically important. The role of this type of magnetite in the sedimentary paleomagnetic record is difficult to assess because of the broad grain size distributions produced and the lack of specific morphologies. We are therefore dependent on magnetic measurements that can detect particles in the SP through stable SD size range. It is possible that data that fall in the 'PSD' field of Day et al. [1977] could result from mixtures of small concentrations of SD grains and larger concentrations of SP particles [cf. Dunlop, 2002] produced by dissimilatory iron reducers. However, multiple processes give rise to particles in this size range. Egli [2004a, $2004 b, 2004 c]$ grouped particles produced by dissimilatory iron-reducers with detrital and pedogenic magnetite because of their similar coercivity distributions. While other magnetic parameters can potentially enable discrimination of such magnetic particles, overlap between the magnetic properties of particles with different origins means that we might sometimes fail to distinguish between different processes responsible for the particles. Nevertheless, in the present paper, we seek to test whether SD particles are common or relatively rare in sedimentary environments, so such ambiguities are tolerable for our present purposes.

[8] Fine-grained authigenic magnetite can also form at moderate temperatures during burial diagenesis [e.g., Jackson et al., 1988; Suk et al., 1990a, 1990b; Jackson et al., 1993; Banerjee et al., 1997; Moreau et al., 2005; Aubourg and Pozzi, 2010]. While magnetite formation during burial could be important for remanence acquisition, this subject is not considered here because we are mainly interested in the magnetic properties of sediments that have not been deeply buried.

\subsection{Pedogenic SD Particles}

[9] Soils and paleosols contain SP/SD magnetite/maghemite particles that form during pedogenesis [e.g., Maher and Taylor, 1988; Zhou et al., 1990]. Magnetic mineral assemblages in soils can have broad grain size distributions [e.g., Liu et al., 2005], with strong contributions from weakly interacting SD particles [e.g., Geiss et al., 2008]. We exclude soils and paleosols from our analysis because they are known to contain SD particles, and our purpose is to explicitly search sedimentary environments where SD particles have not been widely reported. However, it should be recognized that soil-derived particles can be transported into many other sediment types by wind, riverine, and other transportation mechanisms, and that, if they are not altered during transportation or subsequent diagenesis, they are a potential source of SD particles in these environments.

\subsection{Biogenic SD Particles}

[10] Magnetotactic bacteria mineralize membrane-enclosed magnetite or greigite magnetosomes with SD sizes [e.g., Bazylinski and Frankel, 2004; Faivre and Schüler, 2008; Kopp and Kirschvink, 2008] that are ideal for paleomagnetic recording when magnetosomes are incorporated into sediments as magnetofossils. In the years following the discovery of magnetotactic bacteria, they were argued to be widely responsible for paleomagnetic signals in the sedimentary record [e.g., Kirschvink, 1982; Petersen et al., 1986; Stolz et al., 1986; Vali et al., 1987]. However, magnetotactic bacteria are generally gradient organisms that derive energy for growth from the proximity of reductants and oxidants around thin layers near chemical interfaces such as the oxicanoxic transition zone (OATZ) within sediments [e.g., Bazylinski and Frankel, 2004; Faivre and Schüler, 2008; Kopp and Kirschvink, 2008]. Their small particle size means that magnetosomes tend to dissolve after burial when the underlying anoxic sulfidic zone passes through the sediment [e.g., Tarduno, 1994; Housen and Moskowitz, 2006; Torii, 1997; Smirnov and Tarduno, 2000; Yamazaki and Solheid, 2011]. Thus, despite the many species of magnetotactic bacteria and their widespread abundance in aquatic environments, magnetofossils have been reported as the dominant carrier of paleomagnetic signals in few pre-Quaternary locations [Kopp and Kirschvink, 2008].

[11] Magnetosome chains have magnetic behavior that is not intuitively obvious. Alignment of particles into chain structures requires that the individual SD particles strongly interact magnetically [Muxworthy and Williams, 2006, 2009]. This flux linking among magnetosomes produces a strong magnetic anisotropy [e.g., Dunin-Borkowski et al., 1998] that makes the magnetosome chain behave like a single long SD particle with strong magnetic moment. This means that the magnetosome chain only has two stable magnetization states (i.e., positive and negative saturation), as expected for ideal SD particles [Jacobs and Bean, 1955; Penninga et al., 1995;

Figure 2. Day plots [cf. Day et al., 1977] for biogenic and mixed biogenic-terrigenous marine and glaci-marine sediment samples (see Figure 1 for site locations). The biogenic marine sediments are from the Southern Ocean and the mixed biogenic-terrigenous marine sediments are from the Mediterranean Sea. The glaci-marine sediments are from offshore of Antarctica (see site descriptions and cited references in Section 4). 
Terrigenous marine sediments
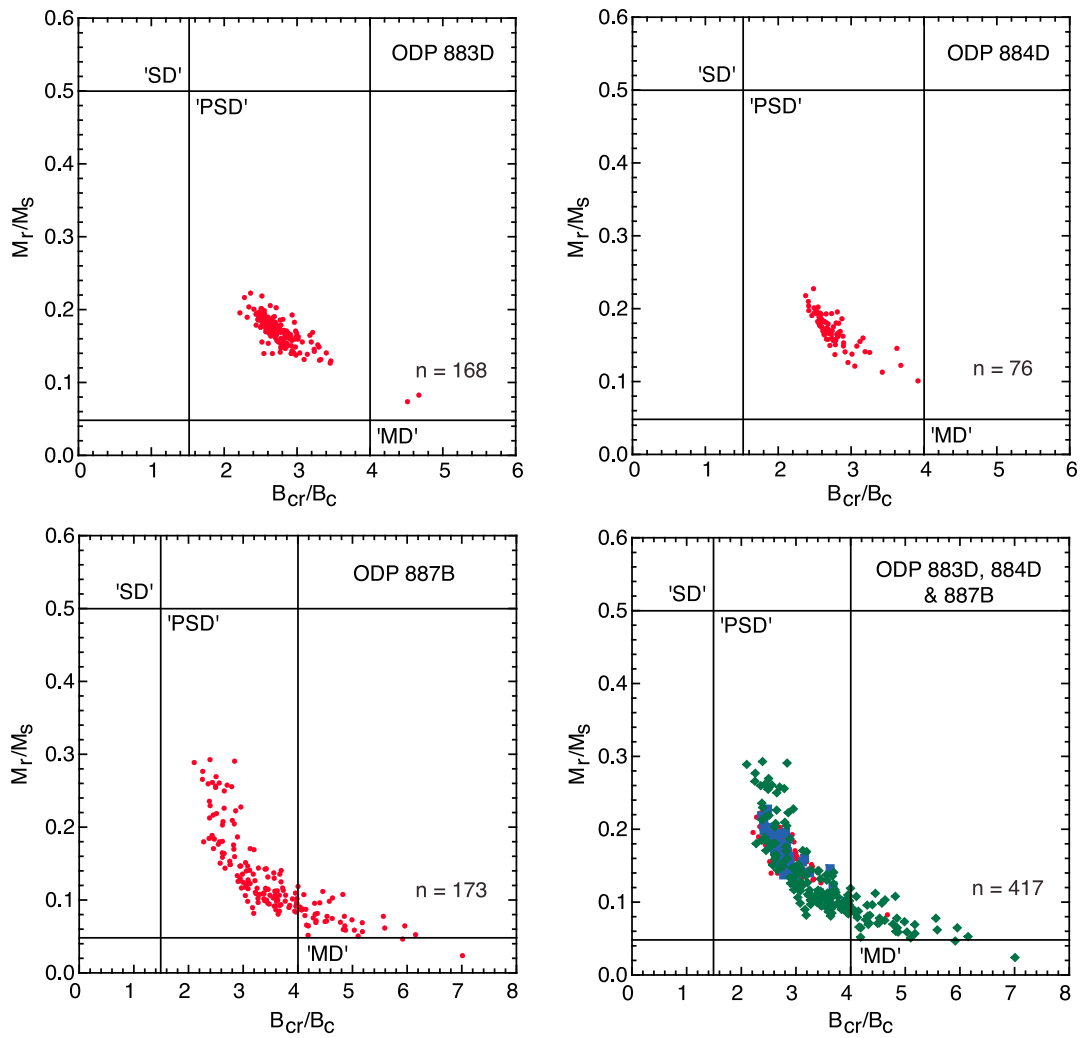

Lake sediments
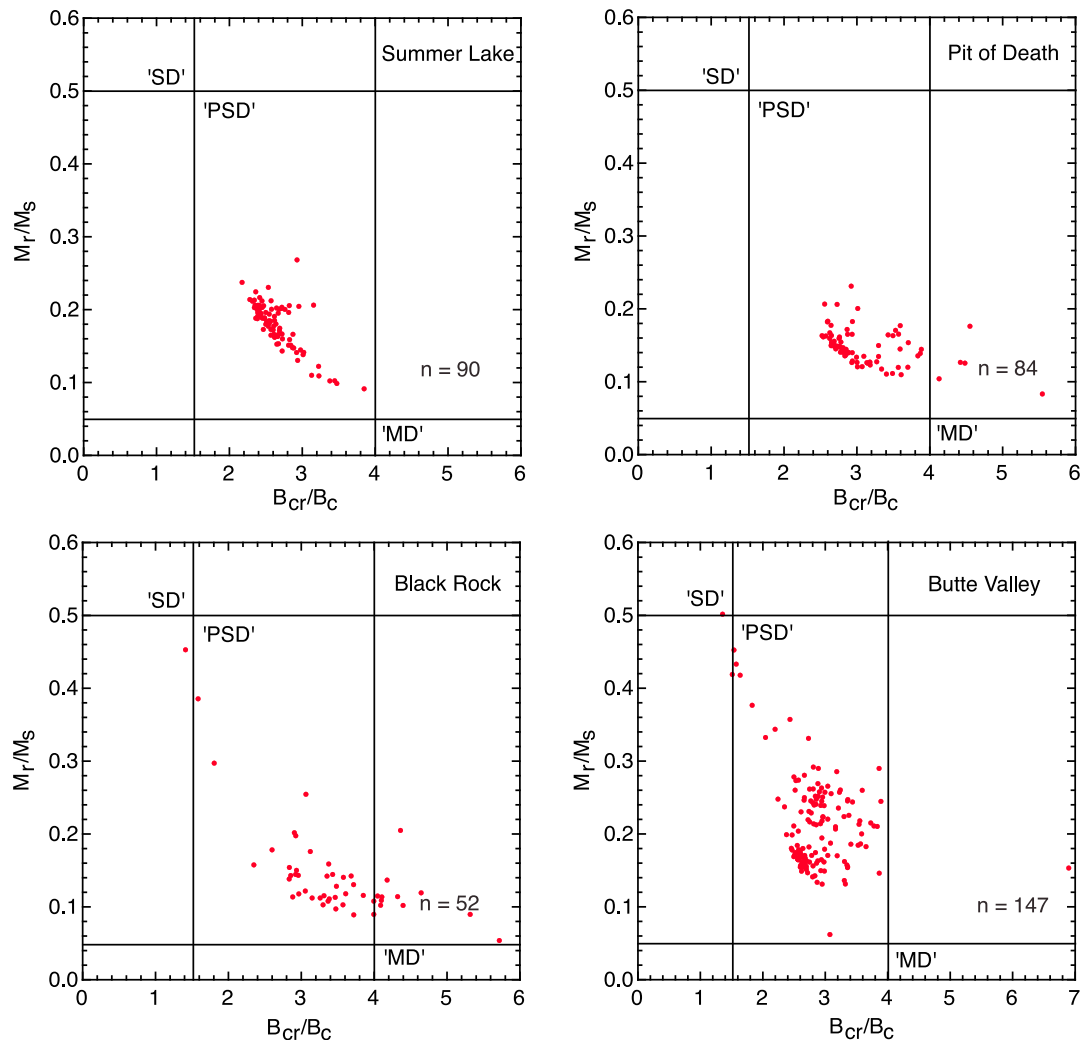

Figure 3 


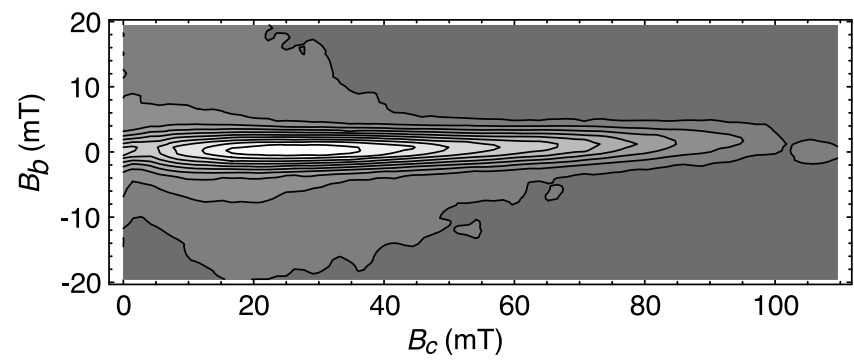

Figure 4. FORC diagram for a fresh, concentrated sample of magnetotactic bacteria grown in the laboratory from samples from Lake Chiemsee, Germany [Petersen et al., 1986; Pan et al., 2005]. The sample contains Magnetotacticum bavaricum with bullet-shaped magnetosomes and cocci that produce cubo-octahedral magnetosomes. The results verify directly the observations of Egli et al. [2010] that intact magnetosome chains give rise to FORC diagrams with a non-interacting central ridge $(\mathrm{SF}=3)$. The broader outer contours at $\sim 20 \mathrm{mT}$ are probably due to collapsed (magnetostatically interacting) chains. This sample was measured in July, 2000; the data were processed with the original code of Pike et al. [1999].

Hanzlik et al., 2002]. This confers distinct magnetic properties on the chains [e.g., Egli et al., 2010]. Magnetic interactions among chains are negligible [e.g., Moskowitz et al., 1993], so intact magnetosome chains in living/recently deceased magnetotactic bacteria therefore produce first-order reversal curve (FORC) distributions [cf. Pike et al., 1999; Roberts et al., 2000] that are indicative of non-interacting SD assemblages with characteristic narrow vertical distributions [e.g., Pan et al., 2005; Chen et al., 2007; Fischer et al., 2008; Carvallo et al., 2009; Li et al., 2009]. These features are illustrated in Figure 4 for magnetotactic bacteria grown in the laboratory (and subsequently separated and concentrated magnetically from sediments in the aquarium used to culture the bacteria). Egli et al. [2010] argued that their FORC measurement protocol, with small field steps between measurements, which enables good resolution of the central ridge in FORC diagrams, is ideally suited for detecting uniaxial SD particles, such as fossil magnetosome chains. Egli et al. [2010] also argued that the selectivity of FORC diagrams for magnetosome detection is unmatched by other magnetic techniques. Several studies have used FORC diagrams to argue for a dominance of sediment magnetic properties by magnetofossils [e.g., Abrajevitch and Kodama, 2009, 2011; Yamazaki, 2008, 2009, 2012; Kind et al., 2011; Roberts et al., 2011a; Larrasoaña et al., 2012], although only the studies of Roberts et al. [2011a], Larrasoaña et al. [2012], and Yamazaki [2012] have verified this interpretation with TEM observations of magnetic mineral extracts from the analyzed sediments. If magnetosome chains are disrupted and magnetite particles interact magnetostatically, the central ridge in the FORC distributions will be vertically spread, as is evident in the broader outer contours at $\sim 20 \mathrm{mT}$ in Figure 4 . Regardless, the presence of SD particles will still be evident in FORC diagrams [e.g., Kind et al., 2011]. Importantly, FORC diagrams enable discrimination of the presence of magnetofossils even when other magnetic minerals are present. For the purpose of determining the extent of preservation of SD particles in sedimentary environments, this is more important than whether the chains have been disrupted. We therefore use FORC diagrams to detect magnetofossils in the present study, but we also use several other methods, as discussed below, as a cross check. This enables us to assess the presence and extent of magnetofossil preservation in different sedimentary environments.

\subsection{Detrital SD Particles}

[12] Detrital particles result from erosion of rocks, and are generally deposited in sediments through fluvial, lacustrine and submarine processes, with grain size distributions that reflect the particular sediment transportation and deposition processes. Additional particles with potentially different grain size distributions can also result from direct input via eolian, volcanic or extraterrestrial fallout. Igneous rocks, which are ultimately the primary source of erosional detritus, contain abundant SD material [e.g., Dunlop, 1972; Heider et al., 1993; Tauxe et al., 1996; Carvallo et al., 2006; Paterson et al., 2010], which makes them an obvious and important source of sedimentary paleomagnetic signals. For example, igneous provinces around the North Atlantic Ocean are likely sources of the superb paleomagnetic records obtained from North Atlantic sediment drift deposits [e.g., Channell and Kleiven, 2000; Kissel et al., 2009]. Nevertheless, a question that arises from the data shown in Figures 2 and 3 is whether detrital SD magnetite is abundant in sedimentary records, or whether a magnetic mineral assemblage is volumetrically dominated by coarser-grained PSD and MD magnetite that mirrors the bulk sediment grain size.

[13] Volcanic ash represents a potential source of detrital SD material in regions down-wind of significant explosive volcanic activity [e.g., Heider et al., 1993]. Wind-blown dust is likely to contain a range of particle sizes and is not necessarily likely to discriminate toward the finest sizes, but eolian processes remain a possibility for delivering SD particles, including pedogenic SD particles, to sediments. Extraterrestrial fallout is possible, but is unlikely to be a volumetrically significant source of magnetic particles in most environments [e.g., Lanci et al., 2012]. Extreme individual events are possible, but strong evidence is needed to

Figure 3. Day plots [cf. Day et al., 1977] for terrigenous marine and lake sediments (see Figure 1 for site locations). The terrigenous marine sediments are from the North Pacific Ocean and the lake sediments are from western North America (see site descriptions and cited references in Section 4). 
support interpretations involving magnetizations arising from such particles. For example, Kent et al. [2003] postulated that SD magnetite particles in Paleocene-Eocene thermal maximum (PETM) sediments from the New Jersey coastal plain resulted from a comet impact that triggered the PETM. Lippert and Zachos [2007] and Kopp et al. [2007] demonstrated that this SD magnetite is biogenic in origin. Likewise, the postulated presence of SD magnetite from disseminated volcanic ash in sediments surrounding Kerguelen Plateau in the Southern Ocean [Heider et al., 1993] is now known to be due to biogenic magnetite [Roberts et al., 2011a]. These cases demonstrate the importance of diagnosing the processes that give rise to the presence of SD magnetite particles.

\subsection{What About SD Hematite and Goethite?}

[14] Hematite and goethite have weak intrinsic magnetizations [e.g., Dunlop and Özdemir, 1997], which means that these minerals have a large grain size range over which SD behavior is observed. Their weak magnetizations also minimize the likelihood of magnetostatic interactions [Muxworthy et al., 2005; Roberts et al., 2006]. When hematite and goethite occur within sediments, they are therefore highly likely to exist in the non-interacting SD state. While these minerals can be useful indicators of a range of environmental processes, their weak spontaneous magnetizations also mean that when magnetite is present, sediment magnetic properties are likely to be dominated by magnetite. Of the results shown in Figures 2 and 3, magnetite has been demonstrated to be the dominant magnetic mineral present; hematite and/or goethite are present in some samples, but not in sufficient quantities to significantly influence the hysteresis data. Our focus in this paper therefore legitimately remains on the search for SD magnetite in sedimentary environments.

\section{Methods}

[15] If we are to make better sense of hysteresis data in the PSD field of Day et al. [1977], it is important to discriminate between SD and other domain states in mixed magnetic mineral assemblages that may or may not magnetostatically interact with each other and that may or may not contain thermally unstable particles. In our search for SD magnetite, we have analyzed previously studied samples with magnetic mineral assemblages that are known to be dominated by magnetite (Figures 2 and 3), and we use techniques that enable direct detection of SD magnetite. We use four main techniques. First, we use FORC diagrams [Pike et al., 1999; Roberts et al., 2000] because they enable direct identification of the presence of SD particles even if they are mixed with non-SD, thermally unstable or magnetostatically interacting magnetic particles. Egli et al. [2010] demonstrated that magnetically non-interacting uniaxial SD particles have a unique signature in FORC diagrams and argued that highresolution FORC diagrams are more powerful than other unmixing methods for detecting uniaxial SD particles. Second, we use ferromagnetic resonance (FMR) measurements, which have been demonstrated to provide diagnostic information concerning the presence of intact magnetosome chains within sediments [Weiss et al., 2004; Kopp et al., 2006; Mastrogiacomo et al., 2010; Charilaou et al., 2011; Kind et al., 2011; Gehring et al., 2011; Roberts et al., 2011a;
Chang et al., 2012]. FMR measurements are sensitive to the narrow SD size distribution of magnetosomes and to variations in magnetic anisotropy; alignment of magnetosomes in chains increases the magnetic anisotropy of a sample, which makes this technique particularly suitable for detection of intact chains of SD magnetosomes in sediments. Third, we use low-temperature magnetic measurements during field cooling (FC) and zero field cooling (ZFC) to detect fossil magnetosomes, following Moskowitz et al. [1993]. Fourth, we use $M_{r}$ acquisition curve analysis [Robertson and France, 1994; Kruiver et al., 2001; Heslop et al., 2002]. Unmixing of $M_{r}$ acquisition curves enables detection of the presence of SD materials regardless of whether they have a biogenic origin [Egli, 2004a, 2004b, 2004c]. When fossil magnetosomes are indicated to be present by the other techniques employed, we also made transmission electron microscope (TEM) observations to verify interpretations and to avoid an approach based entirely on magnetic "remote sensing."

[16] FORC measurements were made with Princeton Measurements Corporation (PMC) instruments, including AGM and VSM models in different institutions. Highresolution FORC diagrams were obtained by measuring up to 247 FORCs with maximum applied fields of $1 \mathrm{~T}$, field increments of up to $0.62 \mathrm{mT}$ and averaging times of 250 $550 \mathrm{~ms}$ depending on the magnetization of the respective samples. The optimal measurement parameters prescribed by Egli et al. [2010] were followed as much as was practicable (the software of Egli et al. [2010] was used to produce FORC diagrams). $M_{r}$ acquisition curves were obtained using the same PMC instruments, with measurements up to maximum applied fields of $1 \mathrm{~T}$. IRM acquisition curves were unmixed [e.g., Robertson and France, 1994] using the procedure of Heslop et al. [2002]. Individual stepwise IRM acquisition curves were smoothed with a constrained least squares spline [de Boor, 1994] before unmixing. The derivative of the spline function was modeled using 3 log-Gaussian distributions that represent separate coercivity components [Robertson and France, 1994]. Optimal distribution parameters $\left(M_{r}, B_{1 / 2}\right.$ and DP) were determined using the algorithm of Heslop et al. [2002]. FMR spectra were measured using an $\mathrm{X}$ band Bruker EMX microspectrometer at the School of Chemistry, University of Manchester, or at the Research School of Earth Sciences, Australian National University (RSES, ANU). For each measurement, 100-200 mg of air-dried sediment was loaded into glass tubes and was microwaved at a frequency of $\sim 9.4 \mathrm{GHz}$ and power of $\sim 0.632 \mathrm{~mW}$. All spectra were integrated over three magnetic field sweeps from 0 to $700 \mathrm{mT}$. Low-temperature magnetic measurements were made using Quantum Designs Magnetic Property Measurement Systems at different institutions. An SIRM was imparted to samples in a $2.5 \mathrm{~T}$ field at $20 \mathrm{~K}$, and was measured in approximately zero field at $5 \mathrm{~K}$ intervals to $300 \mathrm{~K}$ (the residual field after a magnet reset from $2.5 \mathrm{~T}$ is approximately 200-300 $\mu \mathrm{T}$ ). Before imparting the SIRM at $20 \mathrm{~K}$, samples were cooled from $300 \mathrm{~K}$, either under ZFC or FC conditions in a $2.5 \mathrm{~T}$ field. Magnetic particles were extracted from bulk sediment samples for TEM analysis by adapting the methods of Stolz et al. [1986] and Hesse [1994]. Magnetic extracts were viewed and analyzed using a CM300 FEI electron microscope operated at $300 \mathrm{kV}$ at the RSES, ANU. This TEM is equipped with an EDAX Phoenix 
retractable X-ray detector (ultra-thin window) and a Gatan model 694 slow-scan digital camera.

\section{Samples Studied}

[17] Site locations are indicated in Figure 1 for the 3,000+ samples from which data are discussed in this paper. Brief descriptions of the studied sites are provided below; additional details can be found in the papers cited. Most of the respective hysteresis data sets have been published.

\subsection{Deep-Sea Sediments}

[18] ODP Site 738: Samples were studied from pelagic biogenic (mainly calcareous nannofossil and foraminiferal) oozes in two stratigraphic intervals in two holes from ODP Site $738\left(62^{\circ} 42.54^{\prime} \mathrm{S}, 82^{\circ} 47.25^{\prime} \mathrm{E}\right.$; 2,253 m water depth). In Hole $738 \mathrm{~B}$, Eocene sediments were studied from cores $3 \mathrm{H}$ to 12H (16.52-103.46 m below seafloor (bsf)) [Roberts et al., 2011a]. In Hole 738C, we studied the more restricted PETM interval (283.5-286.4 mbsf) [Larrasoaña et al., 2012].

[19] ODP sites 883, 884, and 887: Sites 883 and 884 were cored in close proximity at different water depths down the slopes of Detroit Seamount in the North Pacific Ocean (Hole $883 \mathrm{D}=51^{\circ} 11.898^{\prime} \mathrm{N}, 167^{\circ} 46.128^{\prime} \mathrm{E} ; 2,385 \mathrm{~m}$ water depth; Hole $884 \mathrm{D}=51^{\circ} 27.026^{\prime} \mathrm{N}, 168^{\circ} 20.228^{\prime} \mathrm{E}$; $3,826 \mathrm{~m}$ water depth). Sediments from Hole 884D consist of dark green clays, while those from Hole $883 \mathrm{D}$ have greater abundances of diatoms and $\mathrm{CaCO}_{3}$. Disseminated volcanic ash occurs in sediments from both holes. Site 887 was cored on an elevated surface on the eastern side of the Paton-Murray Seamount group in the Gulf of Alaska $\left(54^{\circ} 21.921^{\prime} \mathrm{N}, 148^{\circ} 26.765^{\prime} \mathrm{W}\right.$; $3,630 \mathrm{~m}$ water depth). The sediments consist of dark gray diatom clays, with interbedded diatom oozes, intermittent volcanic ashes and dropstones. Hysteresis data for the Middle to Upper Pleistocene portion of these sites were presented by Roberts et al. [1995a].

[20] ODP sites 689 and 690: Pelagic sediments were recovered from Maud Rise in the Weddell Sea (Southern Ocean) at ODP sites 689 and 690. Eocene-Oligocene sediments from sites $689\left(64^{\circ} 31.01^{\prime} \mathrm{S}, 3^{\circ} 06.00^{\prime} \mathrm{E} ; 2,080 \mathrm{~m}\right.$ water depth) and $690\left(65^{\circ} 09.62^{\prime} \mathrm{S}, 1^{\circ} 12.29^{\prime} \mathrm{E} ; 2,914 \mathrm{~m}\right.$ water depth $)$ are dominated by nannofossil ooze, with foraminiferal, diatom or siliceous ooze components. A minor terrigenous sedimentary component (probably eolian) has also been reported at these sites. We analyzed samples from the magnetostratigraphic study of Florindo and Roberts [2005].

[21] Core LC07: Piston core LC07 (38 8.72'N, 10 4.73'E; $488 \mathrm{~m}$ water depth) is from the western Sicily Strait in the Mediterranean Sea, and spans the last million years since the Jaramillo Subchron [Dinarès-Turell et al., 2002, 2003]. The recovered sediment is a homogeneous gray to olive gray foraminifer-rich mud and nannofossil ooze. Results are presented for new samples along with data from a detailed environmental magnetic study of core LC07 [Dinarès-Turell et al., 2003].

\subsection{Glaci-marine Sediments}

[22] Victoria Land Basin cores: Magnetic hysteresis measurements have been made on late Eocene through early Miocene sediments from the western margin of the Victoria Land Basin, McMurdo Sound, Ross Sea, Antarctica. The cores and sources of hysteresis data, from the oldest to youngest sediments, are as follows: CIROS-1 lower (i.e., below a major unconformity at $366 \mathrm{mbsf}$ ) [Sagnotti et al., 1998]; CRP-3 [Sagnotti et al., 2001]; CRP-2/2A [Verosub et al., 2000]; CRP-1 [Roberts et al., 1998; Sagnotti et al., 2005]; CIROS-1 upper (i.e., above a major unconformity at $366 \mathrm{mbsf}$ ) (these data are unpublished but are from the sequence studied by Roberts et al. [2003]); and MSSTS-1 (data unpublished). The sediments are dominantly glacimarine in origin, and, as they become progressively younger, they have increasing contributions from volcanic glass sourced from the McMurdo Volcanic Group. The fine-grained (muddy) sediment matrix was sampled in all cases, even in coarse-grained diamictite intervals.

\subsection{Lake Sediments}

[23] Butte Valley: Samples were taken throughout a 102-m core from Butte Valley, Siskiyou County, just south of the Oregon-California border $\left(41^{\circ} 53^{\prime} 37^{\prime \prime} \mathrm{N}, 122^{\circ} 01^{\prime} 28^{\prime \prime} \mathrm{W}\right.$; $1,290 \mathrm{~m}$ above sea level (asl)). The core was taken from a dried lakebed, for which the relict lake is Meiss Lake, which lies southwest of the core site. Roberts et al. [1996] reported paleomagnetic and environmental magnetic data for PlioPleistocene sediments from the Butte Valley core. Stratigraphically restricted occurrences of greigite were documented, but variable concentrations of detrital hematite and magnetite with grain sizes ranging from SP to PSD dominate much of the core [Roberts et al., 1996; Heslop and Roberts, 2012a, 2012b].

[24] Summer Lake: The studied samples are from a 15-m outcrop succession of Middle/Late Pleistocene lacustrine sediments from the Summer Lake sub-basin of ancient Lake Chewaucan, southern Oregon $\left(43^{\circ} 00^{\prime} \mathrm{N}, 120^{\circ} 45^{\prime} \mathrm{W} ; 1277 \mathrm{~m}\right.$ asl). Hysteresis data from these sediments were presented by Roberts et al. [1994].

[25] Black Rock: The studied sediment core was obtained from the top of an early Pleistocene basalt flow that rests on lake sediments east of an abandoned railway siding at Black Rock, Millard County, Utah $\left(38^{\circ} 42^{\prime} 55^{\prime \prime} \mathrm{N}, 112^{\circ} 56^{\prime} 59^{\prime \prime} \mathrm{W}\right.$; $1,503 \mathrm{~m}$ asl). The core extends $273 \mathrm{~m}$ below the lava flow. The Bishop Ash ( 759 ka; Sarna-Wojcicki et al. [2000]) occurs within surficial sediments at the site. The sediment is dominated by mud, which dates through the lowermost Brunhes Chron to the middle Pliocene below the Kaena Subchron [Thompson et al., 1995]. Samples were taken throughout the core, but magnetic results have not been published before.

[26] Pit of Death: The Pit of Death core was recovered from the northwestern margin of the presently dry Sevier Lake Basin $\left(39^{\circ} 02^{\prime} 02^{\prime \prime} \mathrm{N}, 113^{\circ} 13^{\prime} 00^{\prime \prime} \mathrm{W} ; 1,383 \mathrm{~m}\right.$ asl). The Bishop Ash is also present within surficial sediments at this site. The $155-\mathrm{m}$ sediment core is dominated by mud and provides continuous coverage through the lowermost Brunhes Chron to the Gauss Chron in the middle Pliocene [Thompson et al., 1995]. Samples were taken for environmental magnetic analyses throughout the core, but results have not been published before.

\section{Searching for SD Magnetite in Diverse Sedimentary Environments}

[27] In searching for SD grains, and to develop a representative perspective, we consider diverse sedimentary environments. We first evaluate the possible presence and 
preservation of fossil magnetosomes in dominantly biogenic sediments because conventional magnetosomes occur in the ideal SD state and the lower concentration of lithogenic particles in such sediments makes it easier to detect biogenic magnetite. We then consider mixed lithogenic and biogenic sediments, and dominantly lithogenic sediments (e.g., marine and lacustrine clays, and glaci-marine sediments).

\subsection{Dominantly Biogenic Sediments (Pelagic Carbonates)}

[28] Hysteresis data from biogenic marine sediments are the most SD-like of those shown in Figures 2 and 3. Data from ODP sites 689, 690, and 738 consistently fall within the fine-grained end of the 'PSD' field of the Day plot (Figure 2). Representative FORC diagrams for samples from ODP sites 689 and 690 are presented in Figure 5, while FORC diagrams from ODP holes $738 \mathrm{~B}$ and $738 \mathrm{C}$ are presented elsewhere [Roberts et al., 2011a; Larrasoaña et al., 2012]. All of these FORC diagrams have the same features, with a dominant central ridge that is diagnostic of uniaxial non-interacting SD particles that reflect the presence of intact magnetofossil chains [Egli et al., 2010].

[29] FMR spectra from all of these sites are shown in Figure 6 , and are indicative of the presence of magnetofossils. FMR spectra all contain 6 intense and 10 weak lines, which are due to $\mathrm{Mn}^{2+}$ in calcite [e.g., Boughriet et al., 1992; Otamendi et al., 2006]. We used a Fast Fourier Transform to filter high-frequency signals and remove the strong $\mathrm{Mn}^{2+}$ sextet signals (e.g., Figure 6e). The broad spectra have two clear maxima at low applied fields and extend asymmetrically to low fields. The shapes of the measured spectra are associated with magnetically ordered minerals; the asymmetry and the fact that they are shifted to lower fields compared to non-biogenic magnetite makes them distinctive of intact magnetite magnetosome chains [Weiss et al., 2004; Kopp et al., 2006; Fischer et al., 2008; Charilaou et al., 2011; Kind et al., 2011; Gehring et al., 2011; Chang et al., 2012]. The parameters derived from the spectra [Weiss et al., 2004; Kopp et al., 2006] (Figure 6f), are all indicative of intact magnetite magnetosome chains (Table 1; FMR parameters for the studied portions of holes $738 \mathrm{~B}$ and $738 \mathrm{C}$ are provided by Roberts et al. [2011a], Larrasoaña et al. [2012], and Chang et al. [2012]).

[30] Unmixing of IRM acquisition curves [Robertson and France, 1994; Heslop et al., 2002] reveals the presence of a low-coercivity detrital magnetite component, an intermediatecoercvity biogenic magnetite component with low dispersion and a high-coercivity hematite component with wide grain size distribution (Figure 7) for samples from holes 738B and 690C. The biogenic component is dominant in both studied sequences and represents, on average, $50.3 \pm 3.8 \%$ and $66.5 \pm 1.2 \%$, respectively, of the total magnetization. Parameters for the intermediate-coercivity component in these holes (Figure 7) are typical of biogenic magnetite [cf. Egli, 2004b]. We do not have suitable data for IRM component analysis from our published studies of more terrigenous sediments and we have not measured new data here. Overall, however, consistent indications of the presence of SD magnetite from varied data sets (Figures 5-9) indicates that lack of suitable IRM acquisition data will not prevent identification of SD particles from other types of sediments.
[31] Moskowitz et al. [1993] proposed a low-temperature magnetic test for identifying magnetofossils in sediments. The thermal dependence of a low-temperature $(20 \mathrm{~K})$ saturation IRM (SIRM) is measured after ZFC or after cooling in a $2.5 \mathrm{~T}$ field $(\mathrm{FC})$ from $300 \mathrm{~K}$. The difference between the ZFC and FC SIRM on warming through the Verwey transition will exceed 2 for intact chains of unoxidized magnetite magnetosomes, while disruption of the chain structure or conversion of magnetosome surfaces to maghemite reduces the ratio to around 1 [e.g., Moskowitz et al., 1993; Smirnov and Tarduno, 2000; Passier and Dekkers, 2002; Housen and Moskowitz, 2006]. ZFC/FC measurements are shown in Figure 8 for samples from ODP holes 738C, 689D, 690C, and Butte Valley. For samples from Hole $738 \mathrm{C}$, there is a clear difference between the ZFC and FC curves, especially below the Verwey transition temperature, which is consistent with the presence of magnetofossils, while no such difference is evident for samples from holes 689D and 690C. This probably results from the fact that samples from Hole $738 \mathrm{C}$ were fresher than those from holes 689D and 690C at the time of measurement. FORC diagrams and FMR measurements clearly indicate that these sediments contain intact magnetofossil chains. Low-temperature data provide both positive and inconclusive evidence for magnetofossils, probably due to partial oxidation of magnetite to maghemite, which verifies the known limitations of the Moskowitz et al. [1993] test. The generally inconclusive nature of these ZFC/ FC results means that we did not attempt to obtain more comprehensive low-temperature magnetic data sets for other localities studied here.

[32] TEM observations of magnetic extracts from holes 738C and 689D demonstrate that magnetofossils are present in the studied biogenic carbonate sediments (Figure 9). Variable morphologies are observed, including octahedra, cubo-octahedra, hexagonal prisms and bullet-shaped particles that are typical of magnetosome crystals reported from living magnetotactic bacteria [e.g., Petersen et al., 1986; Kopp and Kirschvink, 2008; Li et al., 2010].

[33] While magnetofossils are widely preserved in Holocene and Quaternary carbonate sediments [e.g., McNeill, 1990; Hesse, 1994; Tarduno and Wilkison, 1996; Lean and McCave, 1998; Yamazaki and Kawahata, 1998; DinarèsTurell et al., 2003; Yamazaki, 2009, 2012], they have rarely been reported in pre-Quaternary sediments [Kopp and Kirschvink, 2008] because their small particle size means that magnetosomes tend to dissolve when buried under anoxic conditions [e.g., Tarduno, 1994; Housen and Moskowitz, 2006; Torii, 1997; Faivre and Schüler, 2008]. Data shown in Figures 5-9 are mainly from late Eocene and Oligocene (37 to $24 \mathrm{Ma}$ ) sediments. Magnetofossil preservation within such old sediments results from the fact that pelagic carbonates have optimal environments for preserving bacterial magnetite due to low rates of organic carbon burial and expanded pore water redox zonations, which often do not become anoxic for tens to hundreds of meters below the seafloor [e.g., Tarduno, 1994; Roberts et al., 2011a]. The fact that calcareous oozes are deposited on almost $50 \%$ of the global seafloor, and that marine carbonate rocks crop out extensively on land, indicate considerable global potential for both production of bacterial magnetite and for subsequent preservation of magnetofossils in carbonate-rich sediments. 
(a) ODP 689D-6H-1A-40 cm (66.80 mbsf)

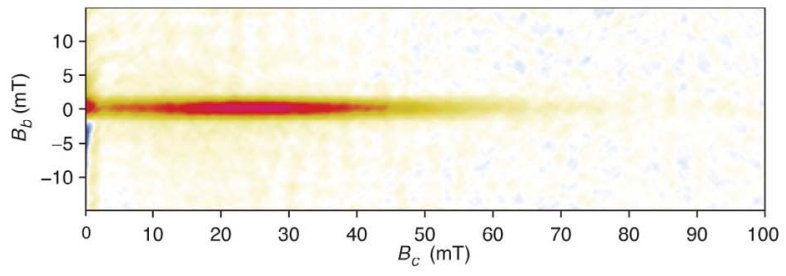

(c) ODP $689 \mathrm{D}-7 \mathrm{H}-2 \mathrm{~A}-110 \mathrm{~cm} \mathrm{~m}(78.60 \mathrm{mbsf})$

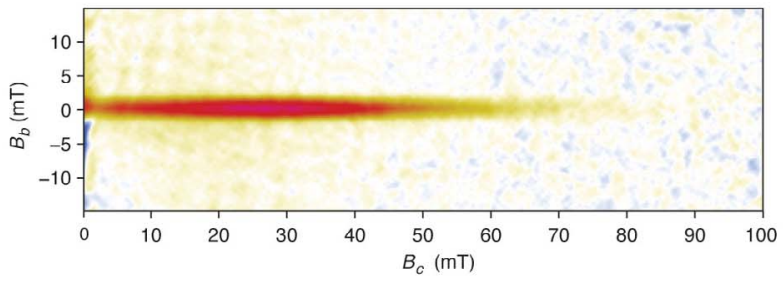

(e) ODP 690C-7H-1A-30 (54.90 mbsf)

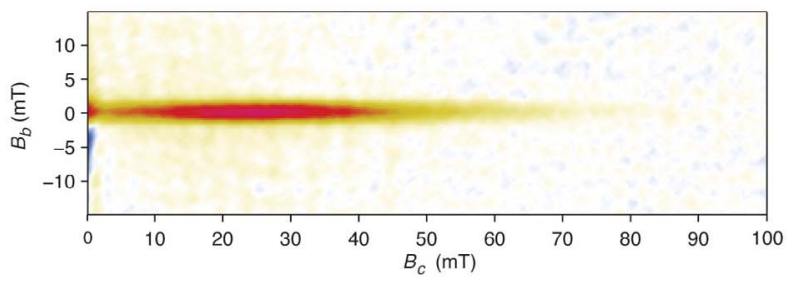

(g) ODP 690C-7H-3W-22 (57.82 mbsf)

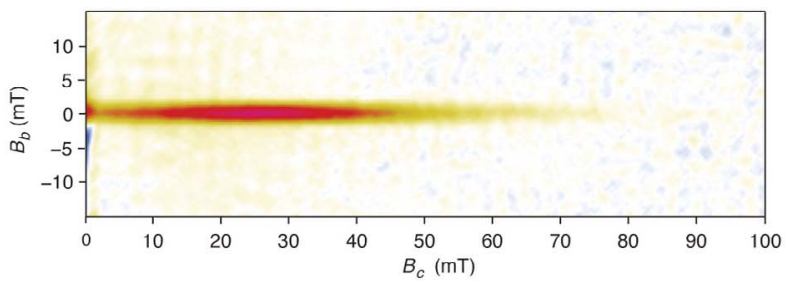

(i) ODP 690C-8H-6A-20 (72.00 mbsf)

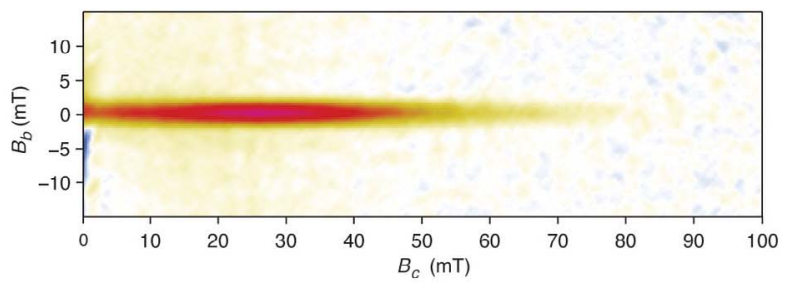

(k)

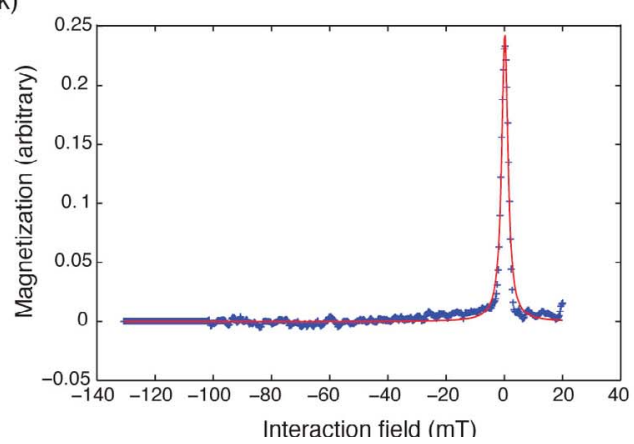

(b) ODP 689D-6H-3A-47 (69.87 mbsf)

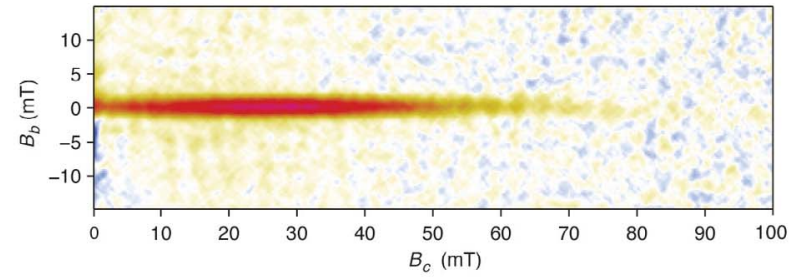

(d) ODP 689D-8H-4A-71 (90.81 mbsf)

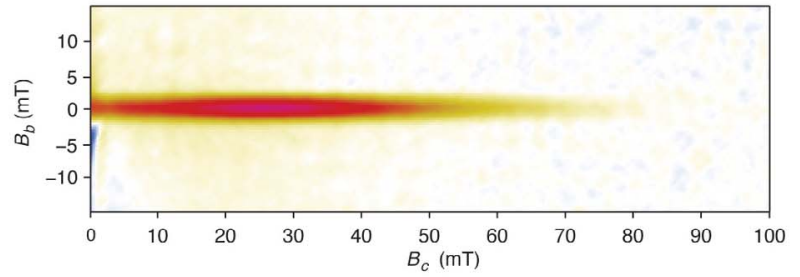

(f) ODP 690C-7H-2A-41 (56.51 mbsf)

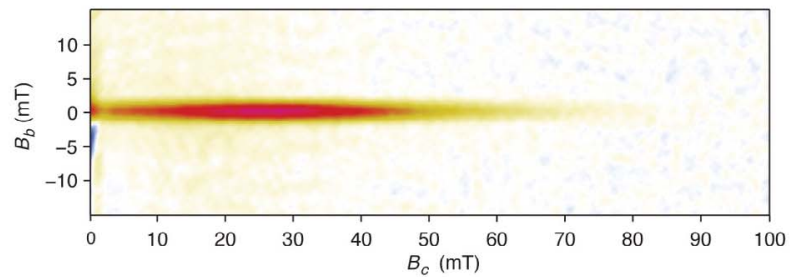

(h) ODP $690 \mathrm{C}-7 \mathrm{H}-4 \mathrm{~A}-81$ (59.91 mbsf)

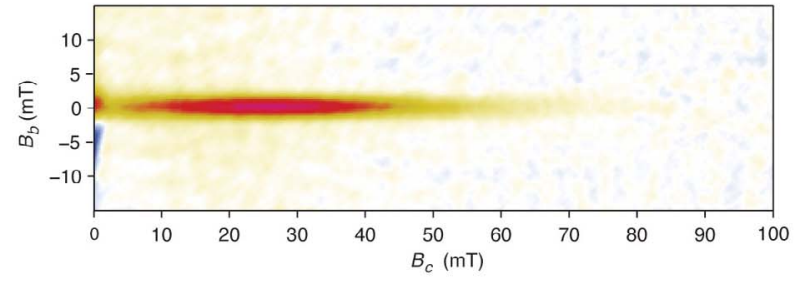

(j) ODP 690C-9H-6A-76 (82.26 mbsf)

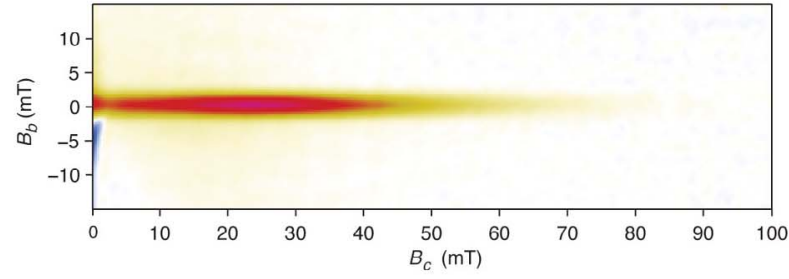

(l)

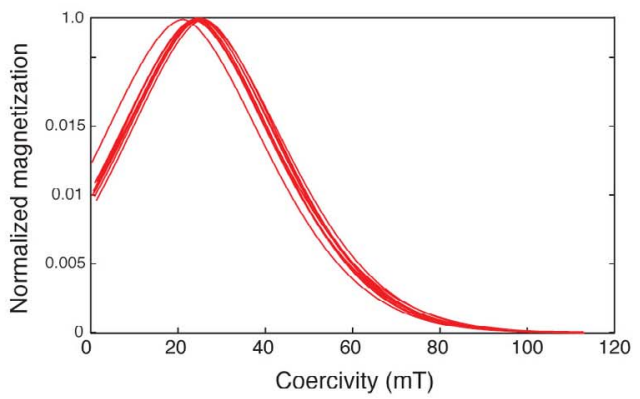

Figure 5 
Table 1. Ferromagnetic Resonance Parameters for the Studied Sediments From ODP Holes 689 and 690

\begin{tabular}{|c|c|c|c|c|c|c|c|c|c|c|}
\hline Sample & Depth (mbsf) & $g_{\text {eff }}$ & $B_{\text {low }}(\mathrm{mT})$ & $B_{\text {high }}(\mathrm{mT})$ & $\Delta B_{\text {low }}(\mathrm{mT})$ & $\Delta B_{\text {high }}(\mathrm{mT})$ & $B_{e f f}(\mathrm{mT})$ & $\Delta B_{F W H M}(\mathrm{mT})$ & $A$ & $\alpha$ \\
\hline 689D-6H2-65 & 68.55 & 1.98 & 260.2 & 405.2 & 78.8 & 66.2 & 339.0 & 145.0 & 0.84 & 0.28 \\
\hline 689D-6H3-47 & 69.87 & 1.97 & 258.3 & 403.9 & 82.3 & 63.3 & 340.6 & 145.6 & 0.77 & 0.27 \\
\hline 689D-6H4-95 & 71.85 & 1.99 & 257.8 & 404.2 & 80.3 & 66.1 & 338.1 & 146.4 & 0.82 & 0.28 \\
\hline 689D-6H5-66 & 73.06 & 2.03 & 235.0 & 395.8 & 96.4 & 64.4 & 331.4 & 160.8 & 0.67 & 0.27 \\
\hline 689D-7H5-44 & 82.44 & 2.01 & 252.4 & 396.7 & 82.4 & 61.9 & 334.8 & 144.3 & 0.75 & 0.27 \\
\hline 689D-7H7-23 & 85.23 & 1.98 & 262.3 & 390.2 & 76.2 & 51.7 & 338.5 & 127.9 & 0.68 & 0.24 \\
\hline 689D-8H6-49 & 93.59 & 2.00 & 241.7 & 390.9 & 93.4 & 55.8 & 335.1 & 149.2 & 0.60 & 0.25 \\
\hline 689D-11H5-104 & 121.44 & 2.00 & 259.4 & 395.2 & 76.4 & 59.4 & 335.8 & 135.8 & 0.78 & 0.27 \\
\hline 689D-12H5-102 & 131.12 & 1.99 & 255.8 & 394.7 & 81.7 & 57.2 & 337.5 & 138.9 & 0.70 & 0.26 \\
\hline $690 \mathrm{C}-7 \mathrm{H} 1-30$ & 54.90 & 2.00 & 248.1 & 393.7 & 87.4 & 58.2 & 335.5 & 145.6 & 0.67 & 0.26 \\
\hline $690 \mathrm{C}-7 \mathrm{H} 2-41$ & 56.51 & 1.97 & 252.3 & 405.7 & 88.3 & 65.1 & 340.6 & 153.4 & 0.74 & 0.28 \\
\hline $690 \mathrm{C}-7 \mathrm{H} 3-22$ & 57.82 & 2.01 & 246.7 & 399.9 & 88.1 & 65.1 & 334.8 & 153.2 & 0.74 & 0.28 \\
\hline $690 \mathrm{C}-8 \mathrm{H} 1-19$ & 64.49 & 2.00 & 251.0 & 397.3 & 85.2 & 61.1 & 336.2 & 146.3 & 0.72 & 0.27 \\
\hline $690 \mathrm{C}-8 \mathrm{H} 6-20$ & 72.00 & 1.97 & 249.9 & 397.4 & 90.7 & 56.8 & 340.6 & 147.5 & 0.63 & 0.25 \\
\hline 690C-9H6-76 & 82.26 & 2.01 & 246.4 & 388.5 & 88.4 & 53.7 & 334.8 & 142.1 & 0.61 & 0.24 \\
\hline
\end{tabular}

The techniques used in this paper, which enable detection of magnetofossils within sediments, should enable much more widespread identification of magnetite magnetofossils in future.

[34] Our data from carbonate sediments indicate that biogenic magnetite is the dominant magnetic mineral in these sediments. The fact that the hysteresis data fall just outside the SD field, and within the 'PSD' field of Day et al. [1977], reflects the contribution of other magnetic particles, including coarser detrital magnetite and hematite [e.g., Roberts et al., 2011a]. The dominant contribution of biogenic magnetite to the magnetic properties of these carbonate sediments makes it reasonable to ask whether the observed magnetofossil signature is a result of a relative lack of terrigenous magnetic material and whether biogenic magnetite or other SD magnetite particles are preserved in non-biogenic sediments. This can be readily tested with climatically modulated mixtures of biogenic and lithogenic sediments.

\subsection{Mixed Biogenic and Lithogenic Sediments}

[35] Hysteresis data from Mediterranean core LC07 [Dinarès-Turell et al., 2003] illustrate the magnetic properties of mixed biogenic and lithogenic marine sediments (Figure 2). There is a climatic influence on the relative contribution of biogenic to coarser-grained detrital magnetite in these sediments, with biogenic magnetite dominating during interglacial periods and detrital magnetite dominating during glacial periods (due to increased eolian dust input during glacials), with magnetofossils clearly indicated by TEM observations [Dinarès-Turell et al., 2003]. FORC diagrams for samples from core LC07 confirm the interpretations of Dinarès-Turell et al. [2003], and indicate the presence of non-interacting SD particles in addition to a variable background magnetic signal due to coarser-grained terrigenous magnetite (Figure 10). Low-resolution FORC diagrams reveal details of the terrigenous component, which has characteristics that are consistent with those of 'PSD' magnetite, particularly the asymmetrical distribution that diverges toward the $B_{b}$ axis in the upper quadrant [Roberts et al., 2000; Muxworthy and Dunlop, 2002]. A clear SD component is also indicated in low-resolution FORC diagrams by the SD peak at $20-30 \mathrm{mT}$, and by the negative peak close to the $B_{b}$ axis in the lower quadrant. Such paired positive and negative peaks on FORC diagrams are characteristic of SD particle systems [Newell, 2005]. The characteristic central ridge associated with SD magnetofossil FORC signatures [Egli et al., 2010] is more clearly evident in highresolution FORC diagrams (Figure 10). The biogenic magnetite signal is clearly evident even when a significant terrigenous magnetic component is present, and bodes well for detection of SD particles using FORC diagrams in dominantly terrigenous sediments.

\subsection{Dominantly Lithogenic Sediments (Lacustrine, Marine, and Glaci-smarine Sediments)}

[36] Results from a wide range of dominantly lithogenic sediments (e.g., lacustrine, marine and glaci-marine environments) are shown in Figures 2 and 3. We now assess representative cases of each of these sediment types to test whether SD magnetite is present.

\subsubsection{Lacustrine Sediments}

[37] We further analyzed samples from a magnetically wellstudied lake sediment core from Butte Valley, California [Roberts et al., 1995b, 1996, 2000; Pike et al., 2001; Heslop and Roberts, 2012a, 2012b]. These sediments are known to contain a complex mixture of lithogenic magnetite (with

Figure 5. FORC diagrams for samples from ODP holes 689D and 690C. (a-j) The FORC diagrams are dominated by a sharp ridge centered on $B_{b}=0$, which is indicative of non-interacting SD magnetic particles [Roberts et al., 2000]. (k) Vertical profile through the peak of a typical FORC distribution, fitted with a Lorentzian function. The sharpness of the ridge indicates a lack of magnetostatic interactions, which is consistent with the presence of intact magnetosome chains [Egli et al., 2010]. (1) Coercivity $\left(B_{c}\right)$ distributions through the peak of the FORC distributions for the 10 samples shown in Figures 5a-5j. The distributions are highly consistent, with peaks at $\sim 25 \mathrm{mT}$, which is within the range of values for bacterial magnetite [Egli, 2004a; Kopp and Kirschvink, 2008]. The scale beside Figure 5a is the same for Figures 5a-5j and is a normalized measure of magnetization. The smoothing factor [Roberts et al., 2000] is 5 in all cases. Depths of samples in the respective holes are indicated in meters below seafloor (mbsf). 

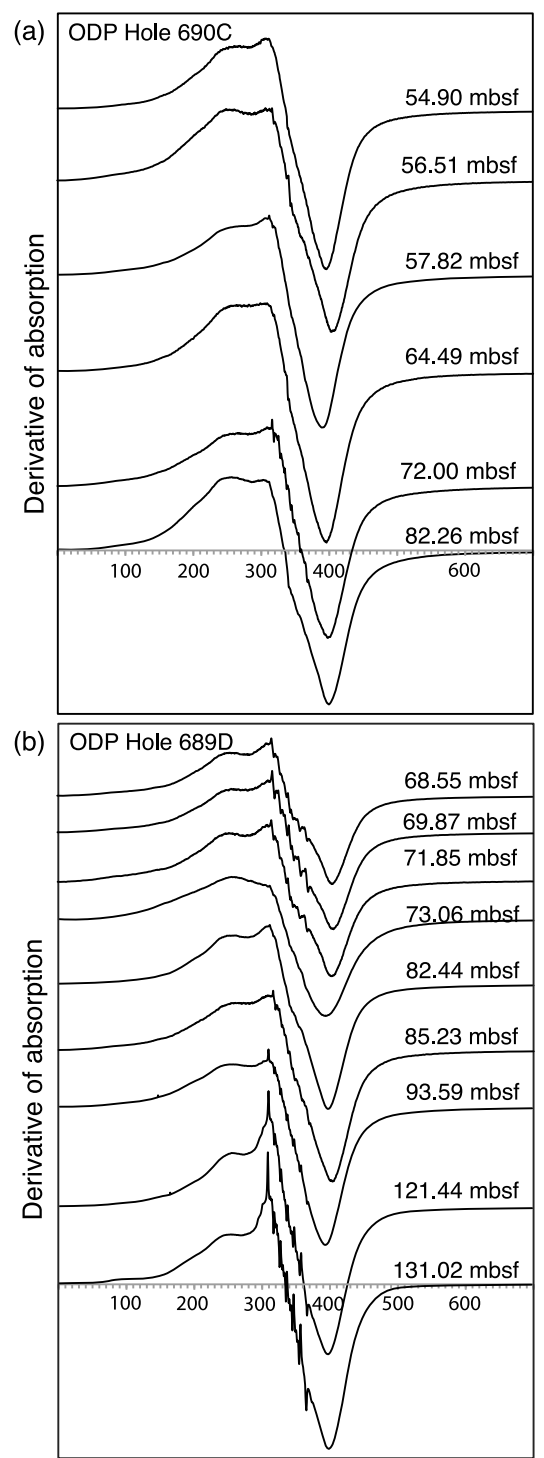

Field (mT)

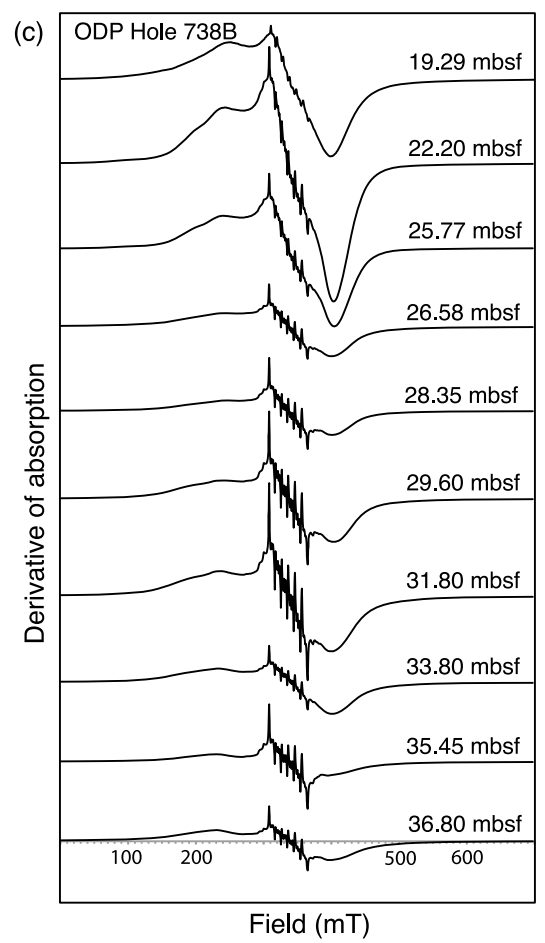

(e)

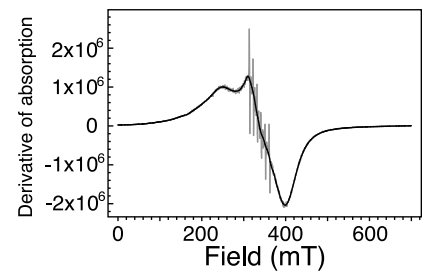

(f)

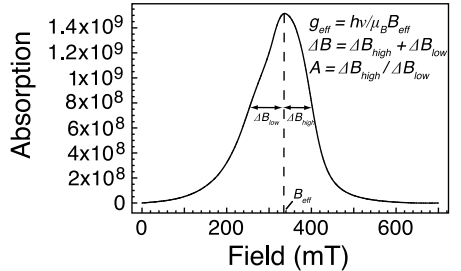

(d)

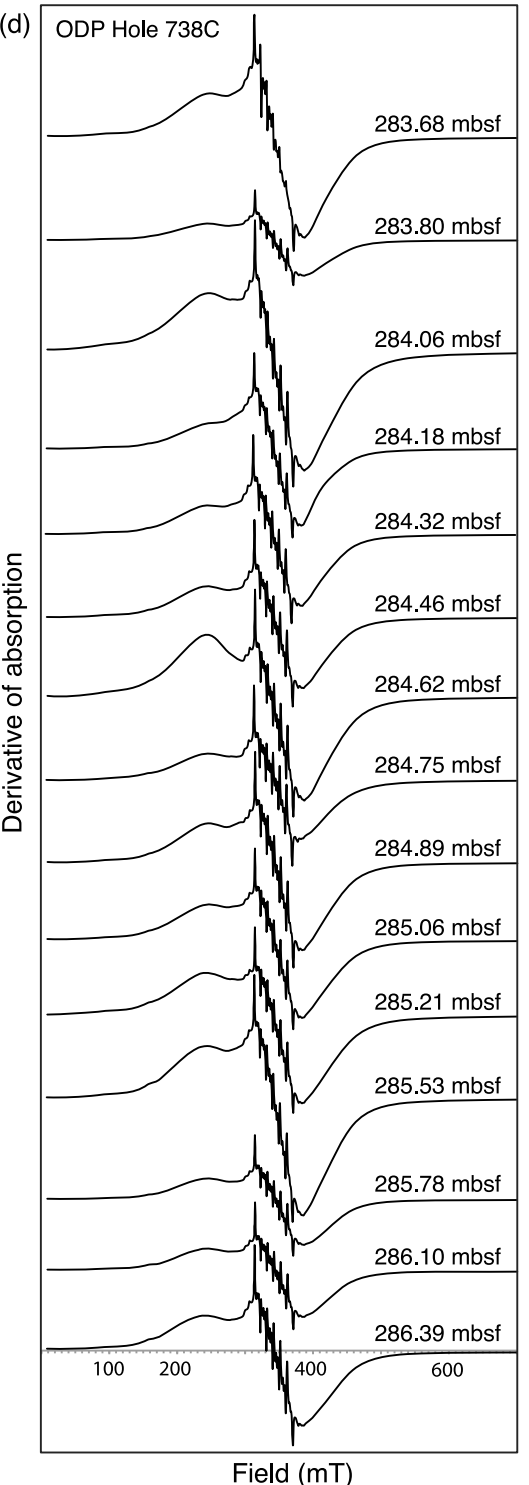

Figure 6. FMR spectra for measured samples from ODP holes (a) 690C, (b) 689D, (c) 738B, and (d) $738 \mathrm{C}$, which provide strong evidence for the presence of intact fossil magnetosome chains. (e) The shaded line represents the measured FMR spectrum, while the black curve fit is after filtering of the high frequency signal using a Fast Fourier Transform. This treatment has not evidently distorted the key features of the FMR signal. (f) Idealized (smoothed) FMR absorption spectrum with definition of parameters that are commonly used to assess the presence of magnetite magnetofossils. FMR parameters for the studied samples are consistent with those of intact magnetosome chains (see Table 1 for ODP 689/690, Roberts et al. [2011a] for ODP 738B and Larrasoaña et al. [2012] for ODP 738C). Each spectrum is normalized by sample mass so that the spectra can be compared directly in stratigraphic order as shown.

SP to PSD sizes), hematite, and authigenic greigite. Heslop and Roberts [2012a, 2012b] applied a new hysteresis unmixing approach to these samples. We selected samples for which a mixed SD/PSD magnetite/hematite end-member (i.e., end-member 1 of Heslop and Roberts [2012b]) is responsible for $40-60 \%$ of the total magnetization. Lowresolution FORC diagrams for such samples (Figure 11) provide evidence of a mixed magnetic mineral assemblage with an asymmetric distribution and considerable vertical spread that is characteristic of PSD particle assemblages [e.g., Roberts et al., 2000; Muxworthy and Dunlop, 2002].
The strong positive peak with coercivity of $20 \mathrm{mT}$ or less, and corresponding negative peak along the $B_{b}$ axis in the lower quadrant of the FORC diagram, are also characteristic of a SD component [Newell, 2005]. Part of the main peak in some of the FORC distributions intersects the $B_{b}$ axis, which results from thermal relaxation in SP particles [Pike et al., 2001] (end-member 2 of Heslop and Roberts [2012b]). Despite the mixed nature of the magnetic mineral assemblage, significant quantities of SD particles are evident in low-resolution FORC diagrams. High-resolution FORC 
(a)
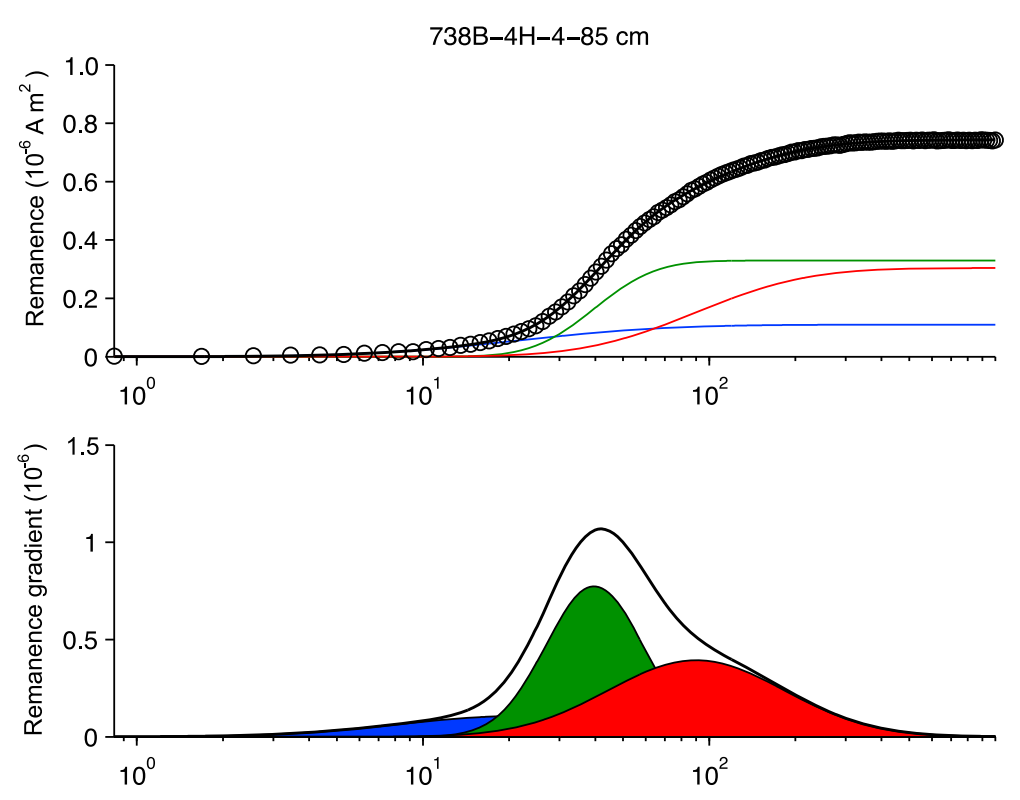

(b)
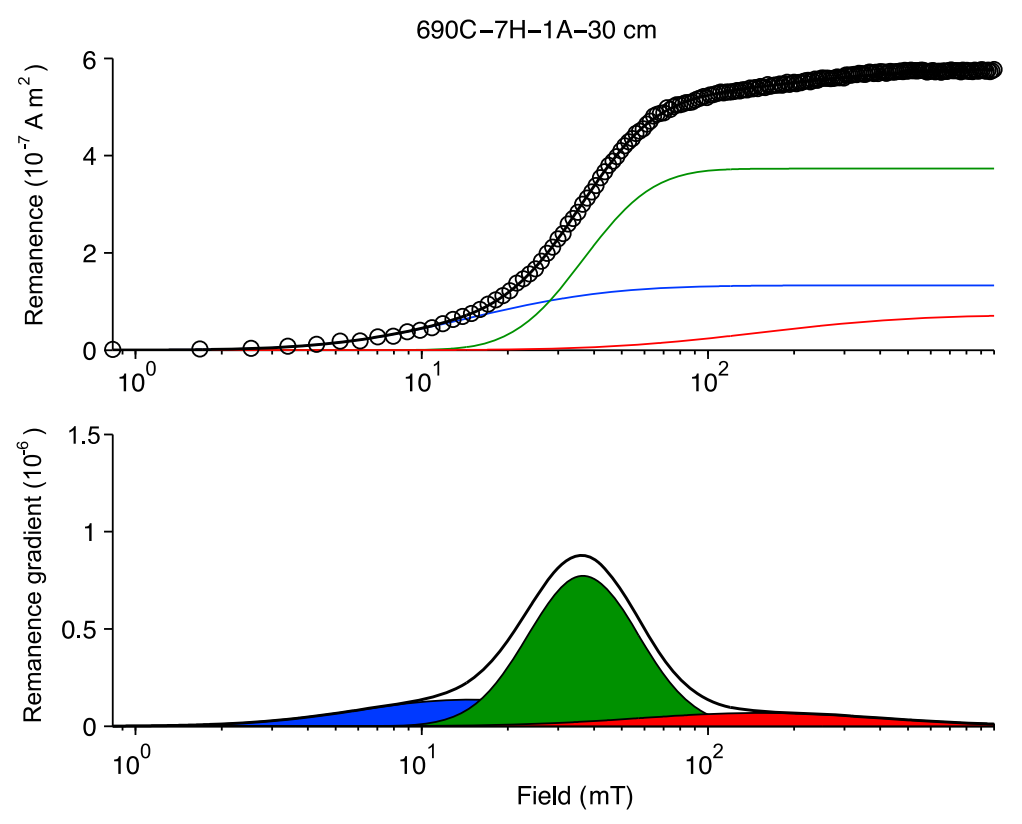

Figure 7. IRM unmixing analyses [Heslop et al., 2002] for representative samples from ODP holes (a) 738B and (b) 690C. The upper plot contains the measured data (black line with circles) and calculated IRM acquisition curves for 3 fitted components after fitting of a spline function. The lower plot contains the derivative curves for each of the three components shown in the upper plot. Blue indicates the low coercivity (detrital magnetite) component, green indicates the biogenic magnetite component, and red indicates the high coercivity (hematite) component. The sum of the three fitted components is plotted in black. The data are normalized so that the integral of the derivative is unity. The dominant biogenic component has a narrow distribution [cf. Egli, 2004b]. The broader lowand high-coercivity distributions are due to detrital (probably eolian) magnetite and hematite, respectively. The high coercivity component has variable coercivities. Average parameters (quoted \pm 1 standard error) for the biogenic component [cf. Heslop et al., 2002] are: Hole 738B - proportion of magnetization = $50.3 \pm 3.8 \% ; B_{1 / 2}=42.0 \pm 1.5 \mathrm{mT}$; and $\mathrm{DP}=0.176 \pm 0.005(\log 10 \mathrm{mT})$; Hole $690 \mathrm{C}-$ proportion of magnetization $=66.5 \pm 1.2 \% ; B_{1 / 2}=37.4 \pm 0.5 \mathrm{mT} ;$ and $\mathrm{DP}=0.193 \pm 0.006(\log 10 \mathrm{mT})$. 
(a)

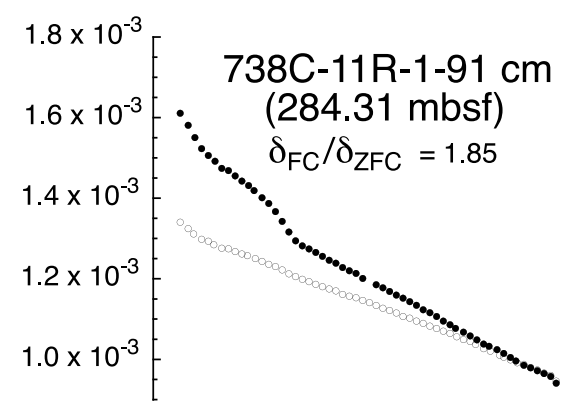

(b)
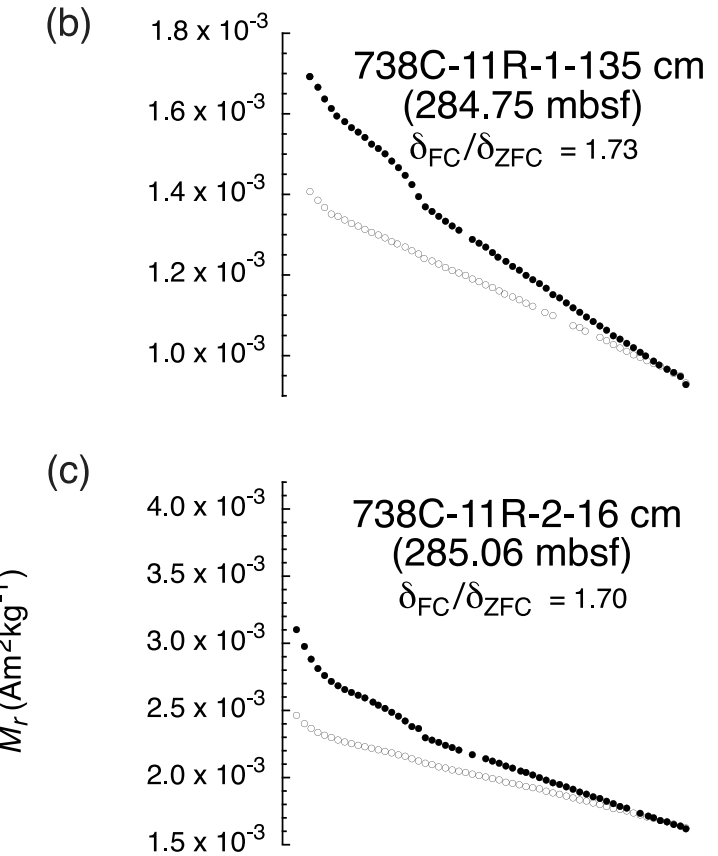

(d)

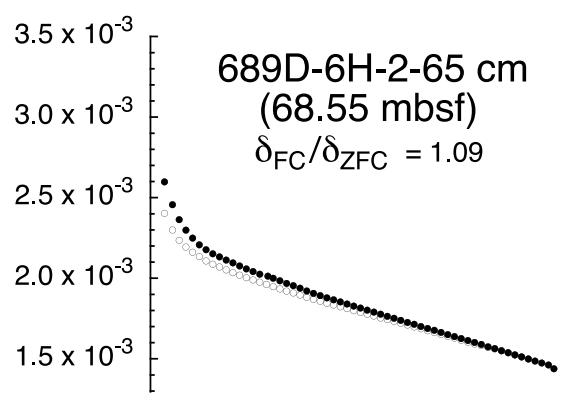

(e)

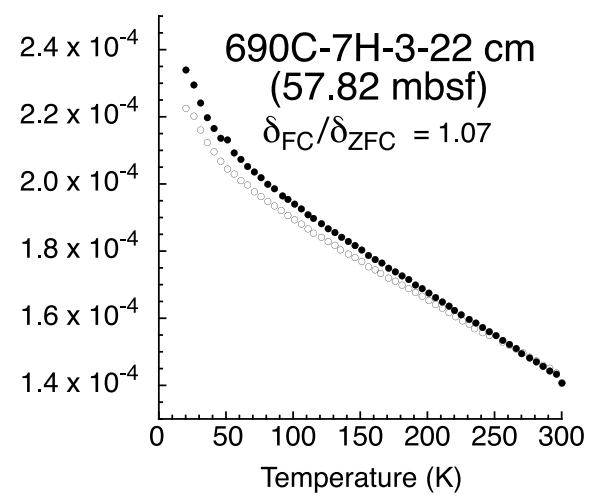

(f)

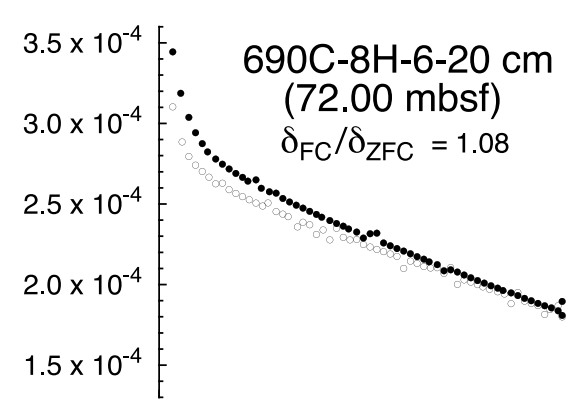

(g)
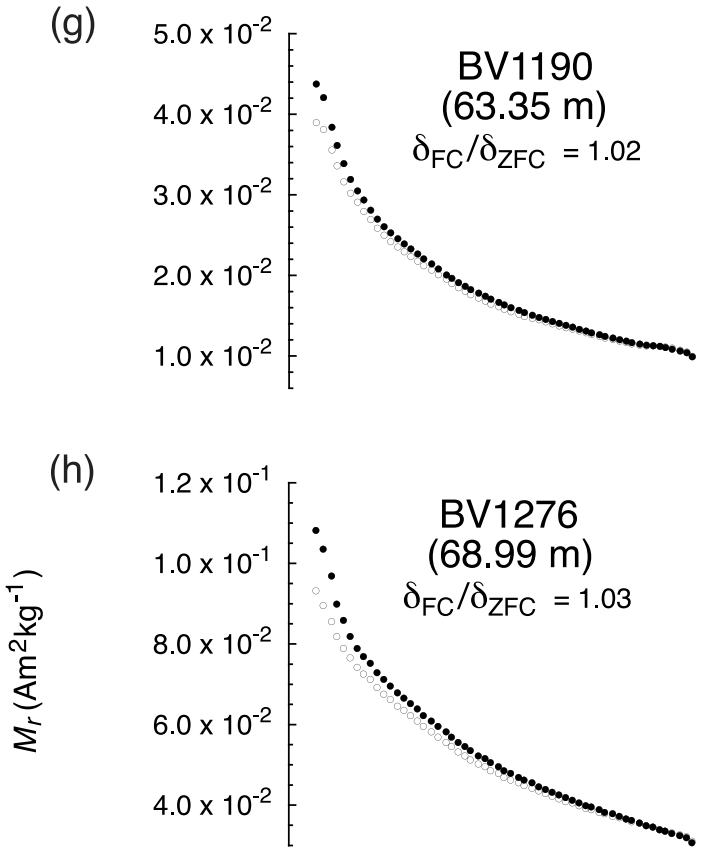

(i)

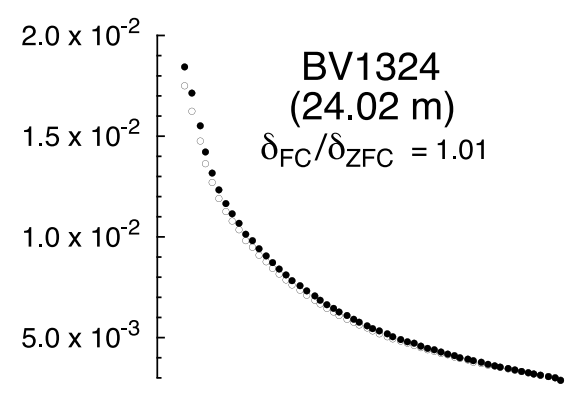

(j)

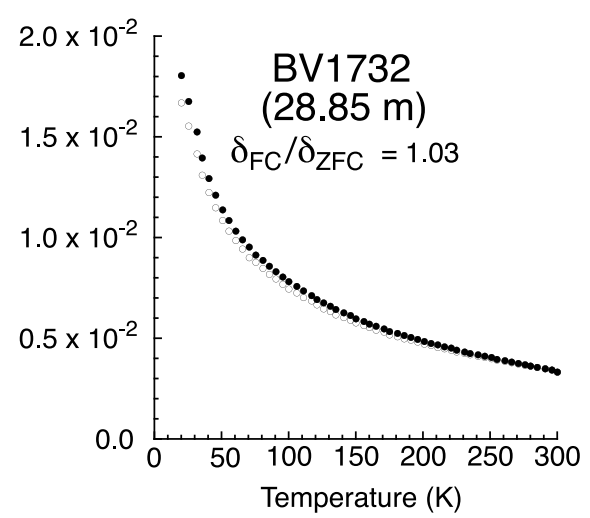

Figure 8 

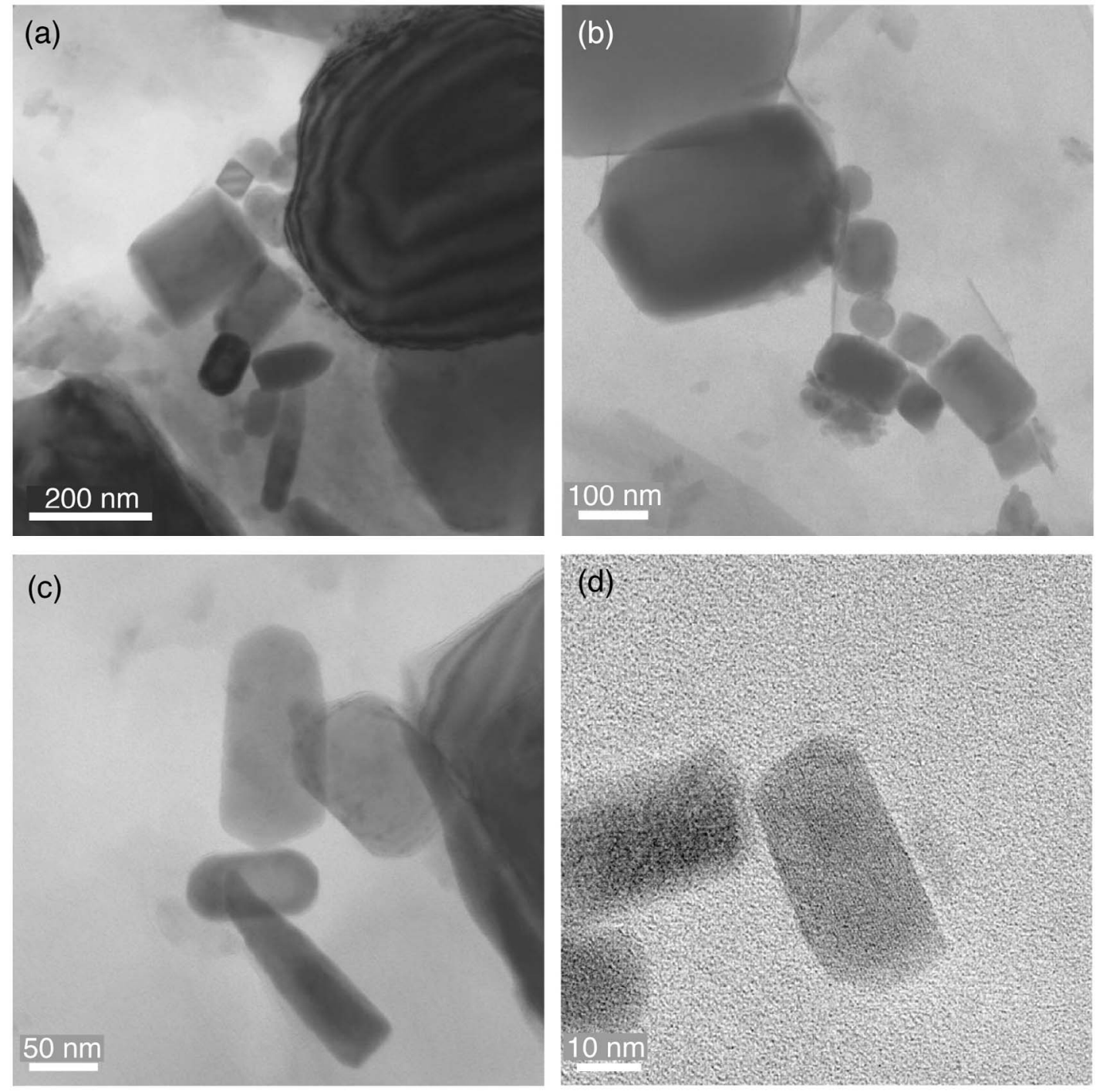

Figure 9. TEM images for magnetic mineral extracts containing direct evidence of fossil magnetosomes. Samples are from (a-c) ODP Hole 738C-11R-2-73 cm; $285.63 \mathrm{mbsf}$ ), and (d) ODP Hole 689D-11H-6-21 cm (122.11 mbsf). The biogenic magnetite particles have a range of typical magnetosome morphologies. Particles with less distinct morphologies are not magnetic. The image in Figure 9d enables resolution of lattice spacings of $3.0 \AA$ ( $\{111\}$ plane). TEM images of biogenic magnetite from ODP Hole 738B are presented by Roberts et al. [2011a] and images from ODP Hole 738C are presented by Larrasoaña et al. [2012].

diagrams, following the measurement protocol of Egli et al. [2010], clearly indicate a sharp central ridge that makes a variable contribution to the total magnetization (Figure 11). This indicates that the SD component is magnetically noninteracting. Low-temperature magnetic analyses of the same samples confirm the presence of a significant SP component (Figures 8g-8j), but the Moskowitz et al. [1993] test does not indicate the presence of magnetite magnetofossils. Again, this is probably due to sample oxidation [e.g., Moskowitz et al., 1993; Smirnov and Tarduno, 2000; Passier and Dekkers, 2002; Housen and Moskowitz, 2006].

[38] Overall, FORC measurements provide a strong indication of the presence of non-interacting SD magnetite particles in the Butte Valley lake sediments, which is probably due to magnetofossils [cf. Egli et al., 2010]. Even with sophisticated rock magnetic measurements, and numerical unmixing of magnetic hysteresis data, this SD component could only be grouped as part of a broader mixed magnetic

Figure 8. Low-temperature FC and ZFC curves, which are used for the Moskowitz et al. [1993] test for fossil magnetosomes in bulk sediment samples. Samples are from (a-c) ODP holes 738C, (d) 689D, (e-f) 690C, and (g-j) Butte Valley. Closed symbols indicate FC curves, while open symbols denote ZFC curves. Values of $\delta_{\mathrm{FC}} / \delta_{\mathrm{ZFC}}$ are shown for each sample following Moskowitz et al. [1993]. See text for discussion. 
(a)
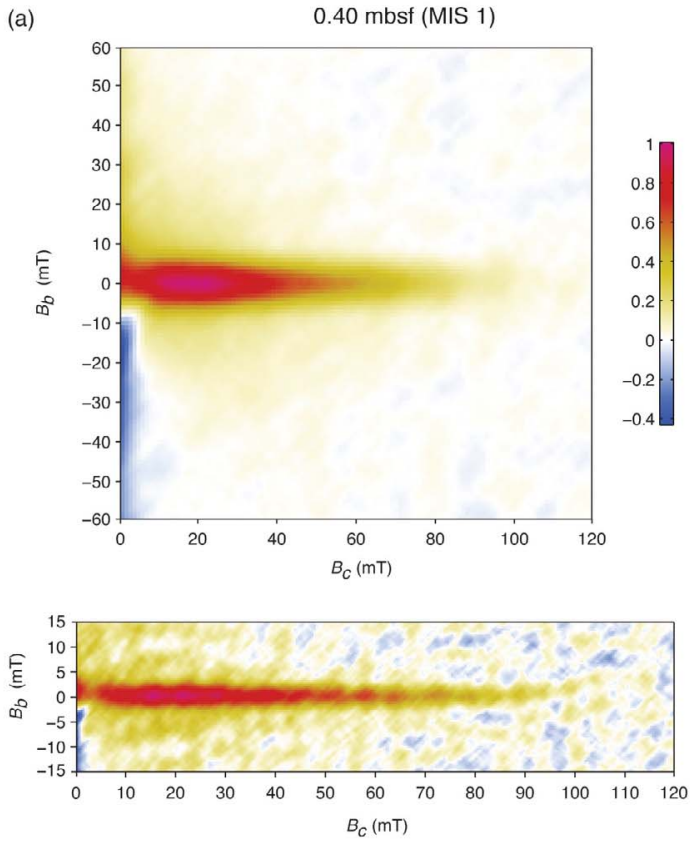

(b)
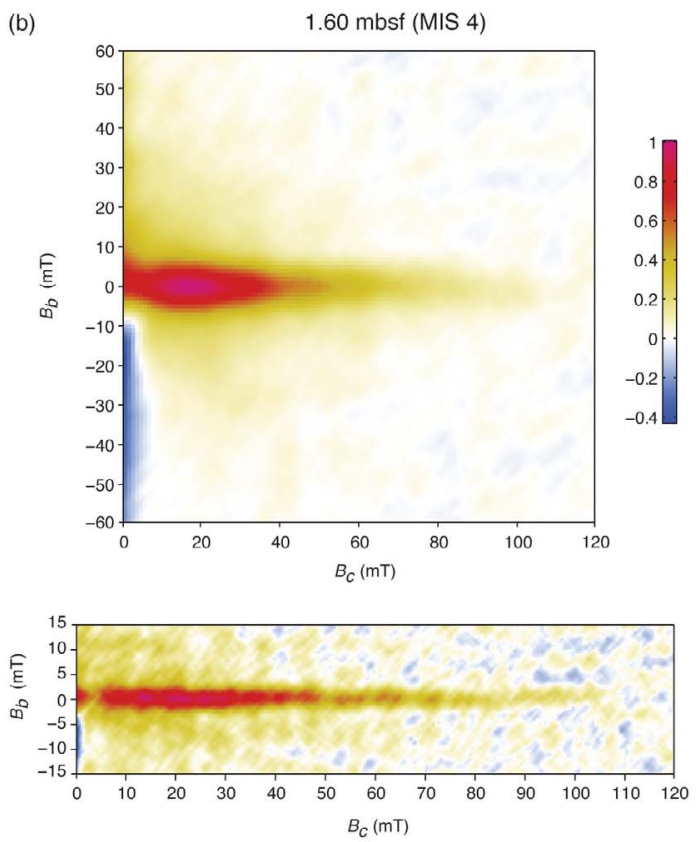

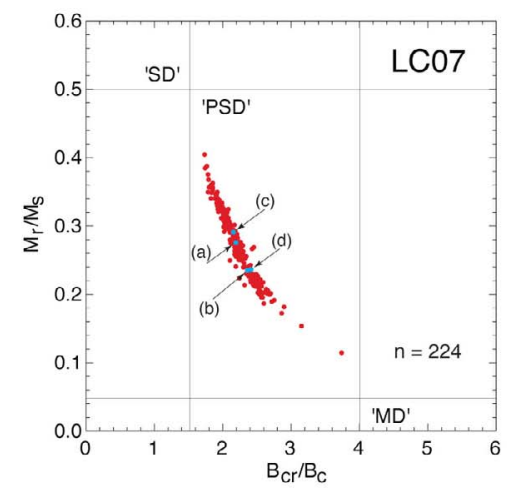

(c)
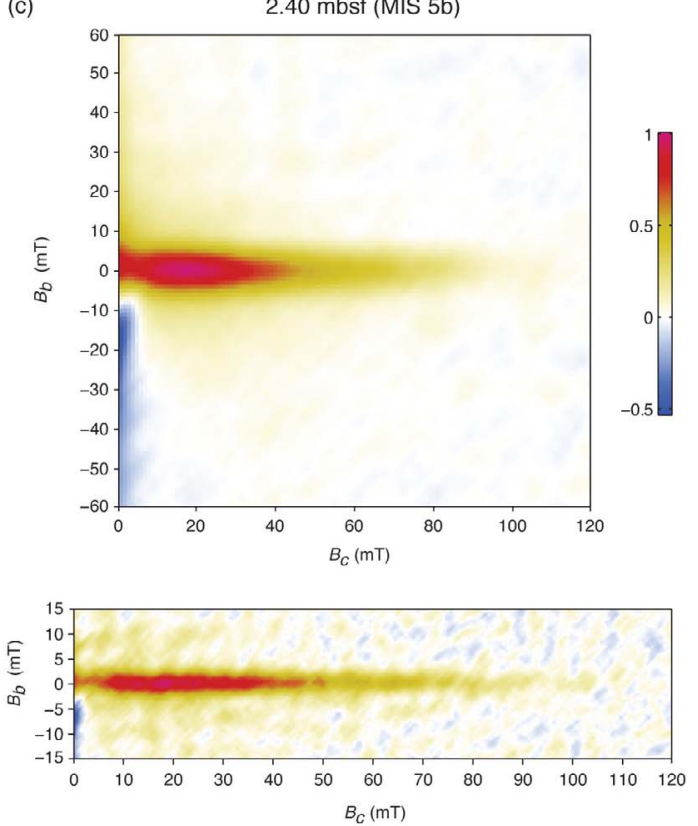

(d)
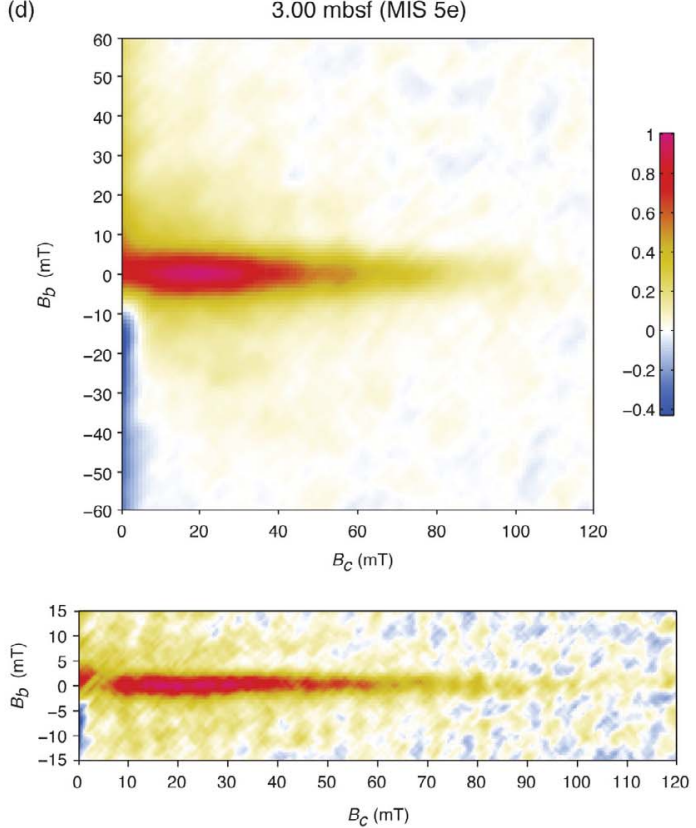

Figure 10 
end-member by Heslop and Roberts [2012b], and was not individually identified as due to non-interacting magnetofossil chains. Roberts et al. [2000] identified a non-interacting SD component in high-resolution FORC diagrams for these sediments, which Egli et al. [2010] suggested was an unrecognized magnetofossil signature. This example demonstrates the value of techniques that enable identification of specific magnetic components. It also indicates that magnetofossil signatures can be significant, and that their presence can be strongly masked by the 'PSD'-like magnetic properties of bulk samples.

\subsubsection{Clay-Rich Marine Sediments}

[39] To test whether clay-rich marine sediments contain significant concentrations of SD particles, we further analyzed samples from ODP Hole 887B from the northeast Pacific Ocean [Roberts et al., 1995a, 2000]. As is the case for the Butte Valley lake sediments, low- and high-resolution FORC diagrams provide evidence for a mixture of PSD and SD magnetite (Figure 12). Again, high-resolution FORC diagrams contain a sharp central ridge, which is consistent with the presence of intact magnetofossil chains [Egli et al., 2010]. In some cases, the FORC distribution is spread vertically at $B_{c}$ values of $\sim 20 \mathrm{mT}$ (Figures $12 \mathrm{c}$ and $12 \mathrm{~g}$ ). This probably reflects disruption of some magnetosome chains. Such spreading has been documented in FORC diagrams (cf. Figure 4) for samples that contain disrupted magnetosome chains [Chen et al., 2007; Egli et al., 2010; Kind et al., 2011]. Regardless, these data indicate that the studied 'PSD'like clay-rich sediments (Figure 3) contain significant concentrations of previously unrecognized magnetite magnetofossils (Figure 12).

\subsubsection{Glaci-marine Sediments}

[40] Glaci-marine sediments from sites near the termination of glaciers are deposited in highly sediment-charged aqueous environments. High terrigenous sediment fluxes and the coarse-grained nature of glacial detritus provide a severe test of our ability to detect SD magnetofossil signatures. To test this possibility, we selected fine-grained intervals from two drill cores from the Victoria Land Basin: cores CRP-1 [Roberts et al., 1998; Sagnotti et al., 2005] and CRP-2/2A [Verosub et al., 2000]. FORC diagrams from these sediments contain a dominant magnetic contribution from PSD-like magnetite (Figure 13). Roberts et al. [2007] reported FORC diagrams for a stratigraphic interval from CRP-2/2A that records a Miocene geomagnetic polarity transition; these FORC diagrams are also dominated by PSD-like behavior. However, unlike the FORC diagrams reported by Roberts et al. [2007], we also observe a SD component that is evident in the paired negative and positive peaks in the lowresolution FORC diagrams [cf. Newell, 2005], and in the strong positive peaks in the high-resolution FORC diagrams (Figure 13). The fact that the negative regions in the lowresolution FORC diagrams in Figure 13 are smaller and weaker than for the other studied sample sets (Figures 10-12) reflects superposition of a relatively stronger positive PSD signal in the lower quadrant of the FORC diagrams with a weaker negative SD signal. In contrast to the other localities discussed above, there is only weak evidence for a central ridge in the high-resolution FORC diagrams from CRP-1 and CRP-2/2A. The FORC distribution peaks consistently occur at $\sim 20 \mathrm{mT}$ and are vertically spread, but they also narrow at higher coercivities. This horizontal 'tear-drop' distribution could indicate significant disruption of magnetofossil chains, with a smaller contribution from non-disrupted chains [Chen et al., 2007; Egli et al., 2010]. However, it could also result from detrital SD magnetite from extrusive rocks of the McMurdo Volcanic Group [Verosub et al., 2000]. We conclude that the stable paleomagnetic signal in the CRP-1 and CRP-2/2A cores [Roberts et al., 1998, 2007; Wilson et al., 2000] is due to detrital SD/PSD magnetite sourced from local igneous rocks. A magnetofossil contribution is possible, but the evidence from FORC diagrams is not as convincing as that from the other studied localities. We have not made ancillary measurements to confirm this possibility. Regardless, significant abundances of SD magnetite clearly exist in the CRP cores despite bulk PSD-like indications from hysteresis measurements.

\section{Discussion}

\subsection{Are SD Particles Common or Rare in Sediments?}

[41] Our results provide evidence for the widespread presence of SD magnetite magnetofossils in many sediment types, ranging from dominantly biogenic pelagic carbonates to mixed lithogenic and biogenic sediments, to dominantly lithogenic sediments, including marine and lacustrine clays, and possibly glaci-marine sediments. For the studied pelagic carbonates and mixed lithogenic and biogenic sediments, the bulk magnetic properties provided enough of a hint of the presence of biogenic SD magnetite that our wide-ranging evidence for their presence (Figures 5-10) was not particularly surprising. Nevertheless, the widespread presence of SD magnetofossils in Eocene-Oligocene pelagic carbonates significantly expands the reported pre-Quaternary record of such particles [cf. Kopp and Kirschvink, 2008]. In contrast, we did not expect to document magnetite magnetofossils in dominantly lithogenic sediments of the various types analyzed. Lithogenic particles evidently make a major contribution to the magnetization of these sediments, but the concentration of SD magnetofossils can also be significant.

[42] Traditional views concerning sedimentary remanence acquisition are dominated by variations around the detrital remanent magnetization (DRM) or post-depositional remanent magnetization (PDRM) concepts. In such a conceptualization, biogenic magnetite might be considered to respond to the ambient magnetizing field in an identical manner to detrital magnetic particles. However, because magnetotactic bacteria live around the OATZ, which often occurs within

\footnotetext{
Figure 10. FORC diagrams for samples from core LC07 from the Straits of Sicily, Mediterranean Sea [Dinarès-Turell et al., 2003]. A 'Day plot' [Day et al., 1977] is shown in the center, with data positions indicated for which FORC diagrams are shown for samples from depths of (a) $0.40 \mathrm{mbsf}$ (from Marine Isotope Stage (MIS) 1), (b) $1.60 \mathrm{mbsf}$ (MIS 4), (c) $2.40 \mathrm{mbsf}$ (MIS 5b), and (d) $3.00 \mathrm{mbsf}$ (MIS 5e). The pair of positive and negative peaks in the low-resolution FORC diagrams indicate the presence of SD grains, while the high-resolution FORC diagrams contain a sharply defined central ridge due to non-interacting SD grains.
} 

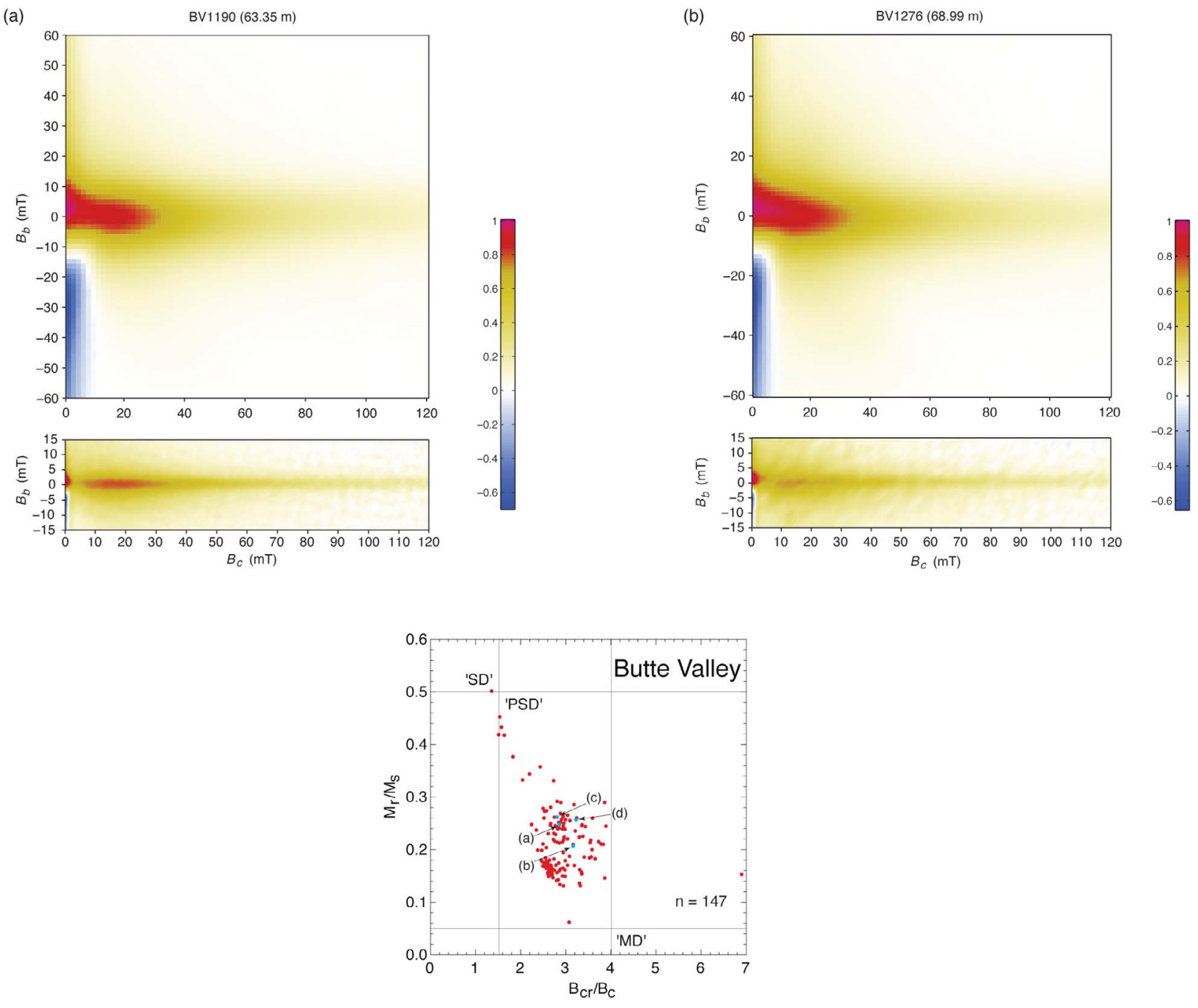
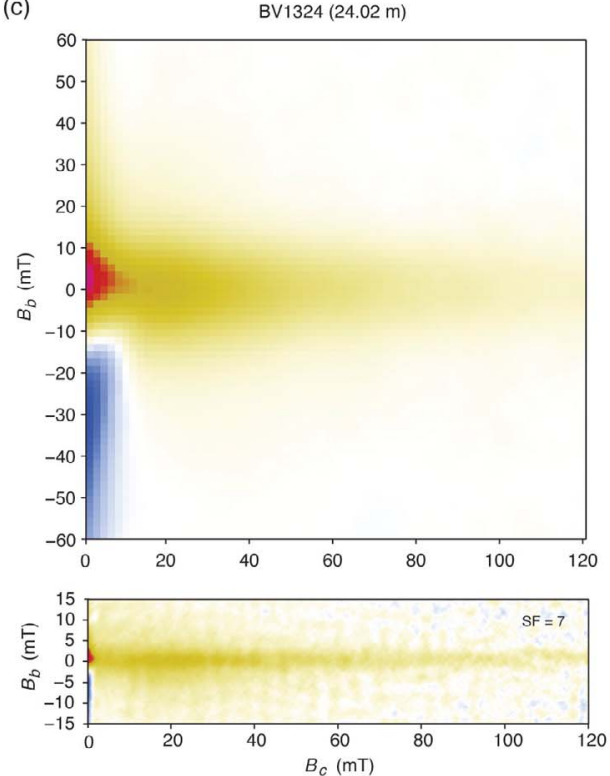

(d)

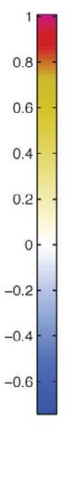

Figure 11 
the sediment, it has been proposed that biogenic magnetite can carry a distinct, and potentially delayed, biogeochemical remanent magnetization [Tarduno and Wilkison, 1996; Tarduno et al., 1998]. Preservation of magnetofossils in sediments could therefore require re-evaluation of how sediments become magnetized, if biogeochemical remanences [e.g., Tarduno and Wilkison, 1996; Tarduno et al., 1998; Abrajevitch and Kodama, 2009], or combinations of depositional and biogeochemical remanences, prove to be widespread. In addition to the common occurrence of magnetite magnetofossils, we provide evidence that sediments proximal to igneous source rocks can also contain significant concentrations of detrital SD magnetite. Overall, our results indicate that SD magnetite particles are not rare in sediments, like needles in haystacks, but that they are relatively common in a wide range of sedimentary environments and that they are commonly due to magnetofossil preservation. This is reassuring and confirms that sedimentary paleomagnetism rests on a solid foundation, which requires that paleomagnetic signals are carried by fine, preferably SD, magnetic particles that can retain records of ancient geomagnetic fields for periods of time approaching the age of the Earth.

\subsection{Do Magnetofossils Cause Bias in Relative Paleointensity Determinations?}

[43] Sediments are widely analyzed for relative geomagnetic intensity studies. There is no firm theoretical basis for relative paleointensity estimation, so empirical criteria have been developed to ensure that a sediment is magnetically "uniform" with a grain size range for which there is evidence for linearity between magnetization and magnetizing field. The criteria are: (i) a consistent remanence acquisition mechanism must have magnetized the studied sequence, (ii) magnetite must be the sole or dominant magnetic mineral responsible for the paleomagnetic signal, (iii) magnetite concentrations must vary by less than an order of magnitude (to minimize paleomagnetic signal degradation by magnetic interactions), and (iv) magnetite must occur within the 1-15 $\mu \mathrm{m}$ (PSD) size range [King et al., 1983; Tauxe, 1993]. We focus on the first and fourth of these criteria.

[44] Paleointensity estimation from sediments is based on the expectation that the remanence is acquired via a DRM or PDRM mechanism (see Tauxe [1993] for a detailed discussion). If, as discussed above, the remanence is a composite (P) DRM and biogeochemical remanence, this will have important implications for paleointensity estimation. As was shown by Dinarès-Turell et al. [2003], biogenic magnetite can be variably diluted by a lithogenic component on glacialinterglacial timescales. It is therefore possible that some of the discrepancies in the paleointensity record for the studied LC07 core compared to other published records [DinarèsTurell et al., 2002] might have resulted from stratigraphically variable contributions from different remanence acquisition mechanisms. The common presence of combined magnetofossil and lithogenic remanence-bearing components in the same sediments suggests that more effort is needed to understand the influence of magnetofossils on the remanence acquisition mechanism in sediments, particularly in relation to relative paleointensity or other high-resolution paleomagnetic analysis.

[45] A further problem for paleointensity studies is that different grain size distributions of lithogenic and biogenic magnetite populations are commonly not discriminated from each other in bulk magnetic measurements. Why is this a problem? Relative paleointensity estimation is based on the expectation that there is a linear relationship between the natural remanent magnetization (NRM) and the strength of the magnetizing field. This requirement only has empirical support for particles in the $1-15 \mu \mathrm{m}$ size range [King et al., 1983; Tauxe, 1993]. In contrast, magnetofossils typically occur in the $30-100 \mathrm{~nm}$ size range for which there is currently no empirical evidence for linearity of NRM with respect to strength of the magnetizing field or with respect to the NRM fraction recorded by particles in the $1-15 \mu \mathrm{m}$ size range. In the case of core LC07 (Figure 10), Dinarès-Turell et al. [2002] reported significant intervals in which the normalized remanence record did not agree well with estimated paleointensities from other records. This could be due to imperfect normalization of the NRM that results from different magnetic responses of lithogenic and biogenic magnetic components. For example, the anhysteretic remanent magnetization (ARM) is widely used to normalize the NRM in relative paleointensity estimations. ARM is most responsive to the SD fraction of a magnetic particle assemblage, so it will bias toward the magnetofossil component rather than the coarser lithogenic magnetite component for which the empirical criteria for paleointensity estimation are designed. Glacial-interglacial variations of the magnetofossil component in core LC07 [Dinarès-Turell et al., 2003] will have a stratigraphically variable effect on ARM, which could cause an irregular bias on normalized intensity records. The widespread presence of magnetofossils, which has largely been ignored in relative paleointensity studies, could therefore cause complications that need to be better understood.

[46] Our results indicate that mixtures of magnetofossils and lithogenic PSD magnetite particles are relatively common (e.g., Figures 5, 10, 11, 12). We have pointed to potential difficulties for relative paleointensity estimation associated with remanence acquisition and normalization parameters for a case that we know well: core LC07. This is unlikely to be an isolated case. Relative paleointensity records have often been reported for pelagic carbonate sediments [e.g., Constable and Tauxe, 1987; Constable et al., 1998; Tauxe and Wu, 1990; Valet and Meynadier, 1993; Tauxe and Shackleton, 1994; Tauxe and Hartl, 1997; Kok and Tauxe, 1999; Yamazaki and Oda, 2005], many of which are from the Ontong-Java Plateau where biogenic

Figure 11. FORC diagrams for samples from Butte Valley, northern California [Roberts et al., 1996]. A 'Day plot' [Day et al., 1977] is shown in the center, with data positions indicated for which FORC diagrams are shown for samples from depths of (a) $63.35 \mathrm{~m}$, (b) $68.99 \mathrm{~m}$, (c) $24.02 \mathrm{~m}$, and (d) $28.85 \mathrm{~m}$. The pair of positive and negative peaks in the low-resolution FORC diagrams indicate the presence of SD grains, while the high-resolution FORC diagrams contain a central ridge due to non-interacting SD grains. 
(a)

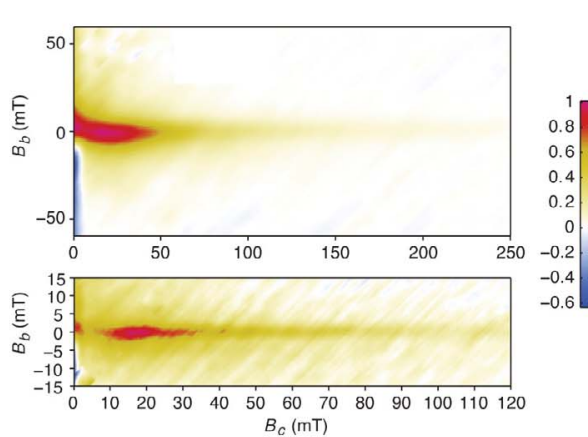

(b)

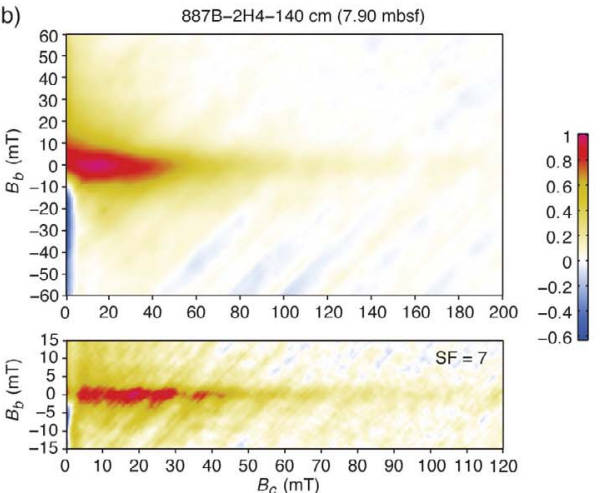

(c)
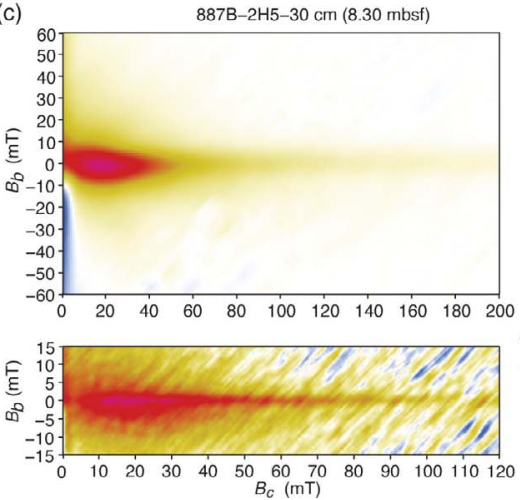

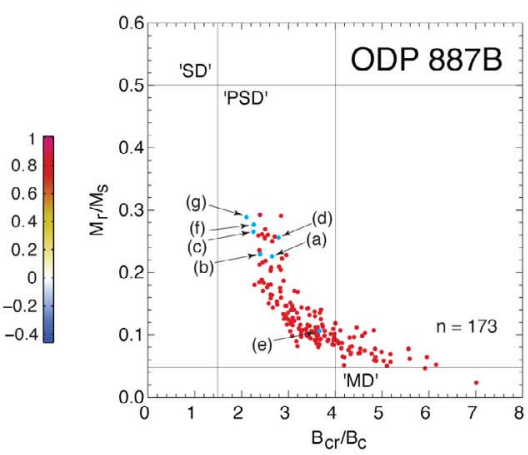

(d)

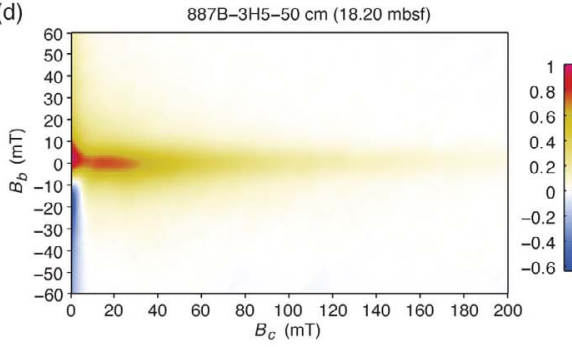

(e)

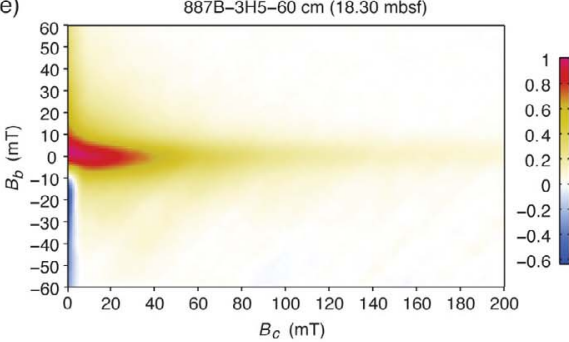

(f)
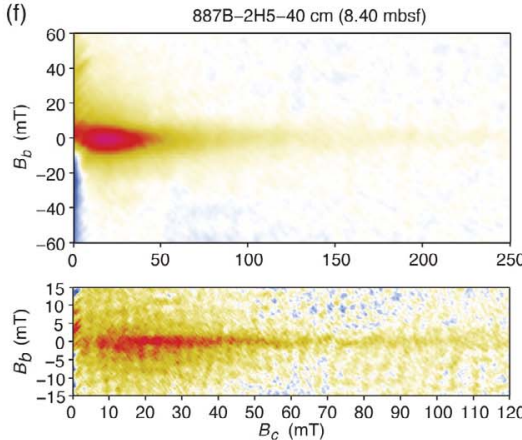

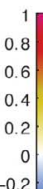

-0.2
-0.4

Figure 12. FORC diagrams for samples from ODP Hole 887B, North Pacific Ocean [Roberts et al., 1995a]. A 'Day plot' [Day et al., 1977] is shown in the center, with data positions indicated for which FORC diagrams are shown for samples from depths of (a) $7.20 \mathrm{mbsf}$, (b) $7.90 \mathrm{mbsf}$, (c) $8.30 \mathrm{mbsf}$, (d) $18.20 \mathrm{mbsf}$, (e) $18.30 \mathrm{mbsf}$, (f) $8.40 \mathrm{mbsf}$, and (g) $8.50 \mathrm{mbsf}$. The positive and negative peaks in the low-resolution diagrams indicate the presence of SD grains, while the high-resolution FORC diagrams contain a central ridge due to non-interacting SD grains.

magnetite is known to be widespread [e.g., Tarduno and Wilkison, 1996; Tarduno et al., 1998; Smirnov and Tarduno, 2000; Yamazaki, 2009; Yamazaki and Solheid, 2011]. Similar considerations are likely to be necessary to understand the effects of different magnetite size fractions on these carbonate paleointensity records.
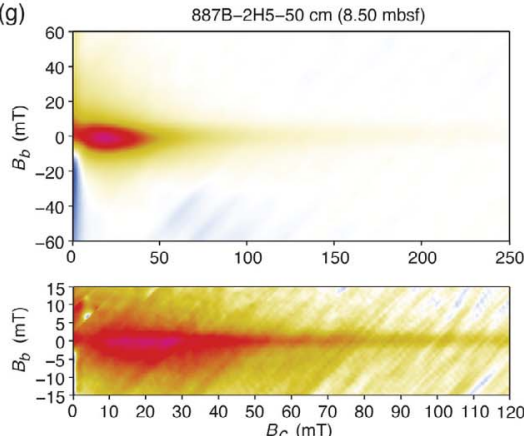

0
-0.2
-0.4
[47] We further illustrate complexities associated with paleointensity estimations from pelagic carbonates in Figure 14. These normalized remanence records are from Eocene-Oligocene carbonates from Maud Rise from which an unambiguous magnetic polarity stratigraphy was derived 

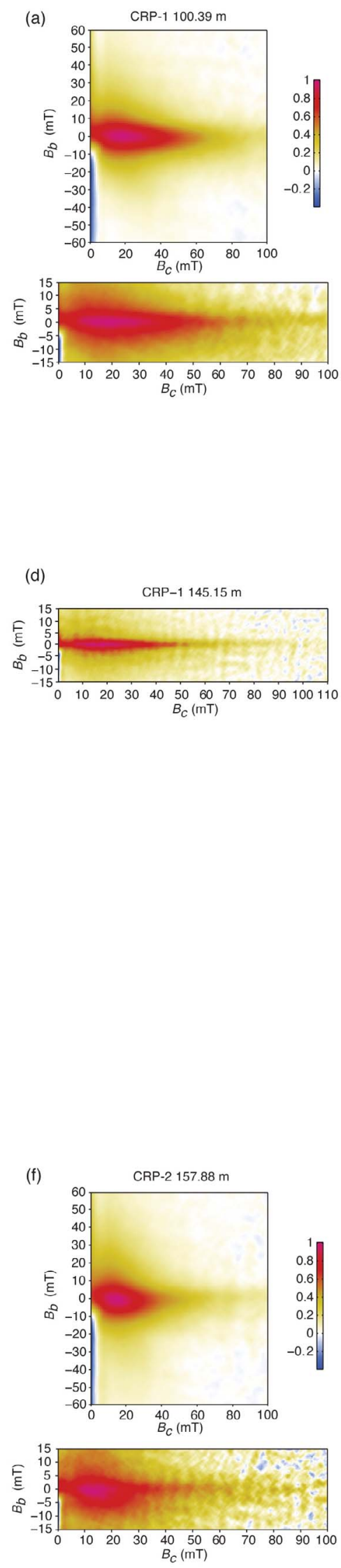

(b)
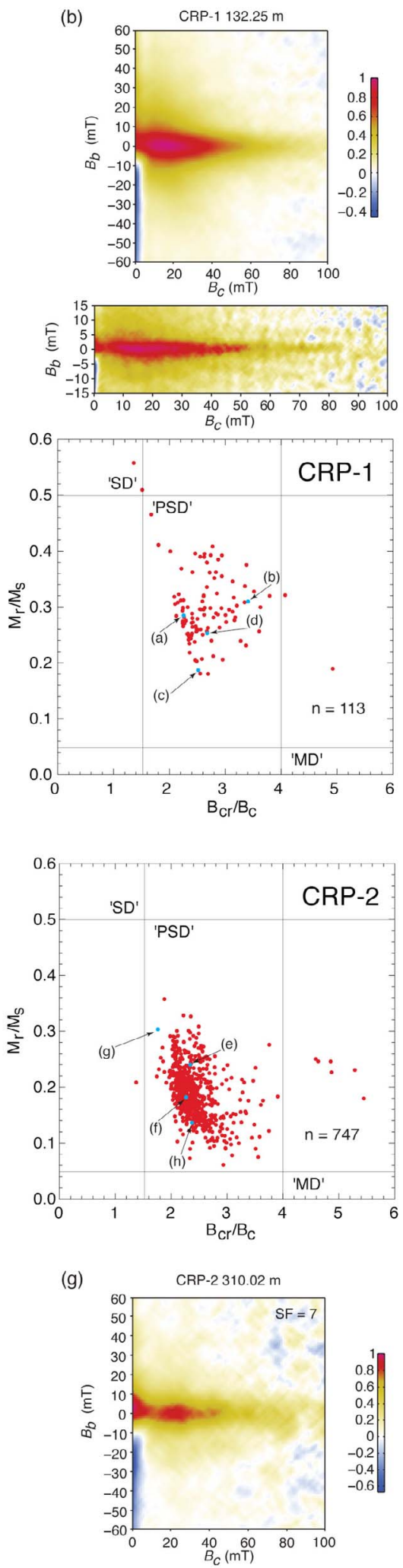
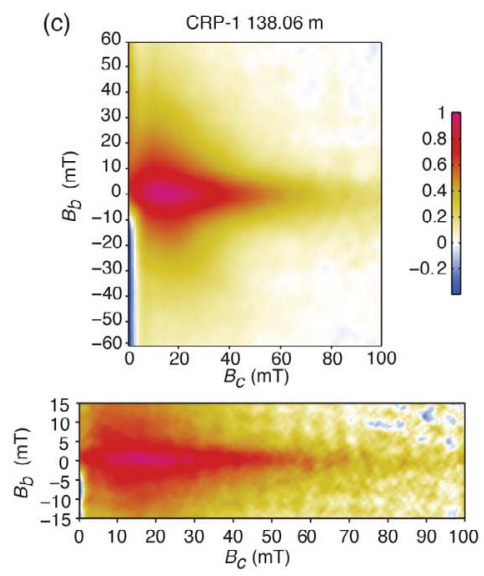

(e)
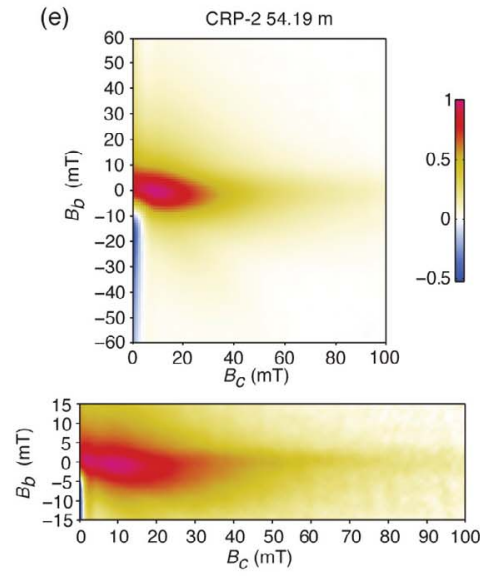

(h)
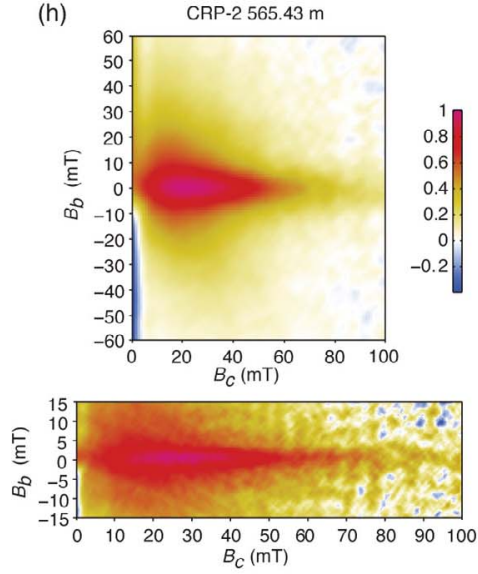

Figure 13 

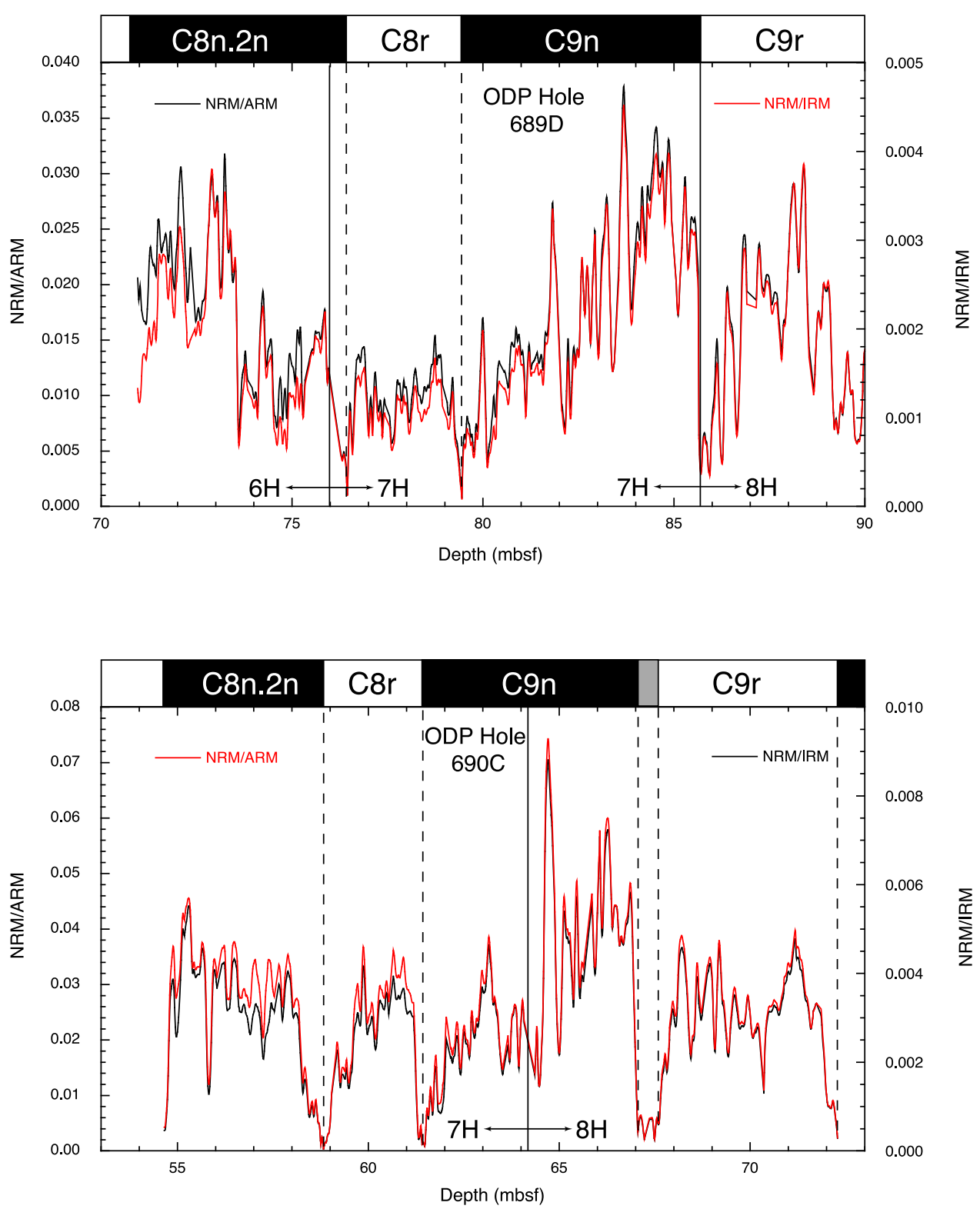

Figure 14. Normalized remanence records (NRM/ARM and NRM/IRM) for correlative parts of the Late Oligocene (chrons C9r to C8n.2n) from ODP holes 689D and 690C, from Maud Rise, Southern Ocean [Florindo and Roberts, 2005]. Despite good agreement between the two normalizations for both holes, and normalized remanence minima at each polarity transition (dashed vertical lines that separate black $=$ normal polarity and white $=$ reversed polarity zones), there is not good agreement between the records from the two holes. Even if 1-2 $\mathrm{m}$ of section has been lost at the indicated core boundaries (solid vertical lines), which is typical of ODP cores [Hagelberg et al., 1995], it remains difficult to correlate the normalized remanence records. See text for discussion.

[Florindo and Roberts, 2005], and for which magnetic properties are reported in Figures 2 and 5-9. The results shown in Figure 14 span late Oligocene chrons C9r through C8n.2n ( 28-26 Ma), an interval that is recorded in both holes 689D and 690C. Apart from minima at the respective polarity transitions, the records do not agree well even when considering that $1-2 \mathrm{~m}$ of sediment is commonly missing in gaps between cores with the advanced hydraulic piston

Figure 13. FORC diagrams for samples from the CRP-1 and CRP-2 drill holes, Victoria Land Basin, Antarctica [Roberts et al., 1998; Verosub et al., 2000]. A 'Day plot' [Day et al., 1977] is shown in the center, with data positions indicated for which FORC diagrams are shown for samples from depths of (a) CRP-1, 100.39 m, (b) CRP-1, $132.25 \mathrm{~m}$, (c) CRP-1, $138.06 \mathrm{~m}$, (d) CRP-1, $145.15 \mathrm{~m}$, (e) CRP-2, $54.19 \mathrm{~m}$, (f) CRP-2, $157.88 \mathrm{~m}$, (g) CRP-2, $310.02 \mathrm{~m}$, and (h) CRP-2 $565.43 \mathrm{~m}$. The pair of positive and negative peaks in the low-resolution FORC diagrams indicate the presence of SD grains. The high-resolution FORC diagrams do not consistently contain a sharp central ridge. 
coring system used by the ODP [Hagelberg et al., 1995]. This discrepancy, for sediments whose magnetic properties are dominated by magnetofossils (Figure 5), suggests that there are complexities associated with remanence acquisition that make them ideally suited for recording paleomagnetic directions, but for which relative paleointensity estimation is not straightforward. The issues outlined above appear to be the most likely for explaining the observed complexities.

[48] The unexpectedly widespread occurrence of magnetite magnetofossils in the geological record points to uncertainties in our understanding of sedimentary remanence acquisition. We conclude that there is an urgent need to develop a better understanding of sedimentary remanence acquisition mechanisms. There is also an urgent need for a more quantitatively rigorous underpinning of sedimentary relative paleointensity estimation. Concluding comments about relative paleointensity normalization by Tauxe and Yamazaki [2007] highlight the urgency of this need: "we can only hope that the normalization procedures chosen will give records that are reasonably linear with the applied field (p. 531)."

\section{Conclusions}

[49] We have analyzed samples with bulk 'PSD'-like magnetic properties from a wide range of sedimentary environments, using a range of techniques that enable detection of SD magnetite particles within mixed magnetic particle assemblages. We have found that SD particles are much more abundant in sediments than has been reported in the literature. In particular, SD particles due to buried bacterial magnetite (magnetofossils) dominate the magnetic properties of pelagic marine carbonates and are common sedimentary constituents even in dominantly lithogenic sediments. Widespread preservation of magnetite magnetofossils requires re-evaluation of the mechanisms by which sediments become magnetized, especially if biogeochemical remanent magnetizations prove to be common, in addition to detrital or post-depositional remanences. Despite the fact that experiments have been conducted for over 60 years (since Johnson et al. [1948]), in an effort to understand the processes by which sediments acquire and retain a remanent magnetization, our results indicate that much remains to be resolved about these important processes.

[50] Acknowledgments. Parts of this work benefited from funding from the UK Natural Environment Research Council grant NE/G003319/1 to A.P.R., Australian Research Council grant DP120103952 to D.H. and A.P.R., and Spanish MEC grant PR2011-0480 to J.C.L. This work benefited from access to facilities at the Kochi Core Centre, Kochi University, Japan, and the Institute for Rock Magnetism, University of Minnesota, USA, as well as at our respective home institutions. We thank Kazuto Kodama, Yuhji Yamamoto, Masayuki Torii, Mike Jackson, Pete Solheid, and Julie Bowles for either providing access, helping with instrument use, or scientific discussions in relation to this work. We thank Nikolai Petersen for providing the fresh magnetotactic bacteria sample used to produce Figure 4 and Chris Pike for measuring the data. We also thank Stuart Gilder (Associate Editor), Ramon Egli, and Toshi Yamazaki for review comments that helped to improve this paper.

\section{References}

Abrajevitch, A., and K. Kodama (2009), Biochemical vs. detrital mechanism of remanence acquisition in marine carbonates: A lesson from the K-T boundary interval, Earth Planet. Sci. Lett., 286, 269-277, doi:10.1016/ j.epsl.2009.06.035.
Abrajevitch, A., and K. Kodama (2011), Diagenetic sensitivity of paleoenvironmental proxies: A rock magnetic study of Australian continental margin sediments, Geochem. Geophys. Geosyst., 12, Q05Z24, doi:10.1029/ 2010GC003481

Aubourg, C., and J. P. Pozzi (2010), Toward a new $<250^{\circ} \mathrm{C}$ pyrrhotitemagnetite geothermometer for claystones, Earth Planet. Sci. Lett., 294, 47-57, doi:10.1016/j.epsl.2010.02.045.

Banerjee, S., R. D. Elmore, and M. H. Engel (1997), Chemical remagnetization and burial diagenesis: Testing the hypothesis in the Pennsylvanian Belden Formation, Colorado, J. Geophys. Res., 102, 24,825-24,842, doi:10.1029/97JB01893.

Bazylinski, D. A., and R. B. Frankel (2004), Magnetosome formation in prokaryotes, Nat. Rev. Microbiol., 2, 217-230, doi:10.1038/nrmicro842.

Boughriet, A., B. Ouddane, and M. Wartel (1992), Electron spin resonance investigations of $\mathrm{Mn}$ compounds and free radicals in particles from the Seine River and its estuary, Mar. Chem., 37, 149-169, doi:10.1016/ 0304-4203(92)90075-L

Carvallo, C., A. P. Roberts, R. Leonhardt, C. Laj, C. Kissel, M. Perrin, and P. Camps (2006), Increasing the efficiency of paleointensity analyses by selection of samples using first-order reversal curve (FORC) diagrams, J. Geophys. Res., 111, B12103, doi:10.1029/2005JB004126.

Carvallo, C., S. Hickey, D. Faivre, and N. Menguy (2009), Formation of magnetite in Magnetospirillum gryphiswaldense studied with FORC diagrams, Earth Planets Space, 61, 143-150.

Chang, L., M. Winklhofer, A. P. Roberts, M. J. Dekkers, C.-S. Horng, L. Hu, and Q. W. Chen (2012), Ferromagnetic resonance characterization of greigite $\left(\mathrm{Fe}_{3} \mathrm{~S}_{4}\right)$, monoclinic pyrrhotite $\left(\mathrm{Fe}_{7} \mathrm{~S}_{8}\right)$ and non-interacting titanomagnetite $\left(\mathrm{Fe}_{3-\mathrm{x}} \mathrm{Ti}_{\mathrm{x}} \mathrm{O}_{4}\right)$, Geochem. Geophys. Geosyst., 13, Q05Z41, doi:10.1029/2012GC004063

Channell, J. E. T., and H. F. Kleiven (2000), Geomagnetic palaeointensities and astrochronological ages for the Matuyama-Brunhes boundary and the boundaries of the Jaramillo Subchron: Palaeomagnetic and oxygen isotope records from ODP Site 983, Philos. Trans. R. Soc. A, 358, 1027-1047, doi:10.1098/rsta.2000.0572.

Charilaou, M., M. Winklhofer, and A. U. Gehring (2011), Simulation of ferromagnetic resonance spectra of linear chains of magnetite nanocrystals, J. Appl. Phys., 109, 093903, doi:10.1063/1.3581103.

Chen, A. P., R. Egli, and B. M. Moskowitz (2007), First-order reversal curve (FORC) diagrams of natural and cultured biogenic magnetic particles, J. Geophys. Res., 112, B08S90, doi:10.1029/2006JB004575.

Constable, C. G., and L. Tauxe (1987), Palaeointensity in the pelagic realm: Marine sediment data compared with archaeomagnetic and lake sediment records, Geophys. J. R. Astron. Soc., 90, 43-59, doi:10.1111/j.1365246X.1987.tb00674.x.

Constable, C. G., L. Tauxe, and R. L. Parker (1998), Analysis of 11 Myr of geomagnetic intensity variation, J. Geophys. Res., 103, 17,735-17,748, doi:10.1029/98JB01519.

Day, R., M. Fuller, and V. A. Schmidt (1977), Hysteresis properties of titanomagnetites: Grain-size and compositional dependence, Phys. Earth Planet. Inter., 13, 260-267, doi:10.1016/0031-9201(77)90108-X.

de Boor, C. (1994), A Practical Guide to Splines (Applied Mathematical Sciences), Springer, New York.

Dinarès-Turell, J., L. Sagnotti, and A. P. Roberts (2002), Relative geomagnetic paleointensity from the Jaramillo subchron to the Matuyama Brunhes boundary as recorded in a Mediterranean piston core, Earth Planet. Sci. Lett., 194, 327-341, doi:10.1016/S0012-821X(01)00563-5.

Dinarès-Turell, J., B. A. A. Hoogakker, A. P. Roberts, E. J. Rohling, and L. Sagnotti (2003), Quaternary climatic control of biogenic magnetite production and eolian dust input in cores from the Mediterranean Sea, Palaeogeogr. Palaeoclimatol. Palaeoecol., 190, 195-209, doi:10.1016/ S0031-0182(02)00605-3.

Dunin-Borkowski, R. E., M. R. McCartney, R. B. Frankel, D. A. Bazylinski, M. Pósfai, and P. R. Buseck (1998), Magnetic microstructure of magnetotactic bacteria by electron holography, Science, 282, 1868-1870, doi:10.1126/science.282.5395.1868.

Dunlop, D. J. (1972), Magnetite: Behavior near the single-domain threshold, Science, 176, 41-43, doi:10.1126/science.176.4030.41.

Dunlop, D. J. (2002), Theory and application of the Day plot $\left(\mathrm{M}_{\mathrm{rs}} / \mathrm{M}_{\mathrm{s}}\right.$ versus $\left.\mathrm{H}_{\mathrm{c}} / \mathrm{H}_{\mathrm{c}}\right)$ : 1 . Theoretical curves and tests using titanomagnetite data, J. Geophys. Res., 107(B3), 2056, doi:10.1029/2001JB000486.

Dunlop, D. J., and Ö. Özdemir (1997), Rock Magnetism: Fundamentals and Frontiers, 573 pp., Cambridge Univ. Press, New York.

Egli, R. (2004a), Characterization of individual rock magnetic components by analysis of remanence curves: 1 . Unmixing natural sediments, Stud. Geophys. Geod., 48, 391-446, doi:10.1023/B:SGEG.0000020839.45304.6d.

Egli, R. (2004b), Characterization of individual rock magnetic components by analysis of remanence curves: 2 . Fundamental properties of coercivity distributions, Phys. Chem. Earth, 29, 851-867, doi:10.1016/S1474-7065(04) 00129-9. 
Egli, R. (2004c), Characterization of individual rock magnetic components by analysis of remanence curves: 3 . Bacterial magnetite and natural processes in lakes, Phys. Chem. Earth, 29, 869-884, doi:10.1016/j.pce.2004.03.010.

Egli, R., A. P. Chen, M. Winklhofer, K. P. Kodama, and C. S. Horng (2010), Detection of noninteracting single domain particles using firstorder reversal curve diagrams, Geochem. Geophys. Geosyst., 11, Q01Z11, doi:10.1029/2009GC002916.

Faivre, D., and D. Schüler (2008), Magnetotactic bacteria and magnetosomes, Chem. Rev., 108, 4875-4898, doi:10.1021/cr078258w.

Fischer, H., G. Mastrogiacomo, J. F. Löffler, R. J. Warthmann, P. G. Weidler, and A. U. Gehring (2008), Ferromagnetic resonance and magnetic characteristics of intact magnetosome chains in Magnetospirillum gryphiswaldense, Earth Planet. Sci. Lett., 270, 200-208, doi:10.1016/j.epsl.2008.03.022.

Flanders, P. J. (1988), An alternating gradient magnetometer, J. Appl. Phys., 63, 3940-3945, doi:10.1063/1.340582.

Florindo, F., and A. P. Roberts (2005), Eocene-Oligocene magnetobiostratigraphy of ODP sites 689 and 690, Maud Rise, Weddell Sea, Antarctica Geol. Soc. Am. Bull., 117, 46-66, doi:10.1130/B25541.1.

Gehring, A. U., J. Kind, M. Charilaou, and I. García-Rubio (2011), The detection of magnetotactic bacteria and magnetofossils by means of magnetic anisotropy, Earth Planet. Sci. Lett., 309, 113-117, doi:10.1016/j.epsl.2011.06.024.

Geiss, C. E., R. Egli, and C. W. Zanner (2008), Direct estimates of pedogenic magnetite as a tool to reconstruct past climates from buried soils, J. Geophys. Res., 113, B11102, doi:10.1029/2008JB005669.

Hagelberg, T. K., N. G. Pisias, N. J. Shackleton, A. C. Mix, and S. Harris (1995), Refinement of a high-resolution, continuous sedimentary section for studying equatorial Pacific Ocean paleoceanography, Leg 138, Proc. Ocean Drill. Program Sci. Results, 138, 31-46.

Hanzlik, M., M. Winklhofer, and N. Petersen (2002), Pulsed-fieldremanence measurements on individual magnetotactic bacteria, J. Magn. Magn. Mater., 248, 258-267, doi:10.1016/S0304-8853(02)00353-0.

Heider, F., U. Körner, and P. Bitschene (1993), Volcanic ash particles as carriers of remanent magnetization in deep-sea sediments from the Kerguelen Plateau, Earth Planet. Sci. Lett., 118, 121-134, doi:10.1016/ 0012-821X(93)90163-4

Heslop, D., and A. P. Roberts (2012a), Estimating best-fit binary mixing lines in the Day plot, J. Geophys. Res., 117, B01101, doi:10.1029/ 2011JB008787.

Heslop, D., and A. P. Roberts (2012b), A method for unmixing magnetic hysteresis loops, J. Geophys. Res., 117, B03103, doi:10.1029/ 2011JB008859.

Heslop, D., M. J. Dekkers, P. P. Kruiver, and I. H. M. van Oorschot (2002), Analysis of isothermal remanent magnetization acquisition curves using the expectation-maximization algorithm, Geophys. J. Int., 148, 58-64, doi:10.1046/j.0956-540x.2001.01558.x.

Hesse, P. P. (1994), Evidence for bacterial palaeoecological origin of mineral magnetic cycles in oxic and sub-oxic Tasman Sea sediments, Mar. Geol., 117, 1-17, doi:10.1016/0025-3227(94)90003-5.

Horng, C. S., and A. P. Roberts (2006), Authigenic or detrital origin of pyrrhotite in sediments?: Resolving a paleomagnetic conundrum, Earth Planet. Sci. Lett., 241, 750-762, doi:10.1016/j.epsl.2005.11.008.

Housen, B. A., and B. M. Moskowitz (2006), Depth distribution of magnetofossils in near-surface sediments from the Blake/Bahama Outer Ridge, western North Atlantic Ocean, determined by low-temperature magnetism, J. Geophys. Res., 111, G01005, doi:10.1029/2005JG000068.

Jackson, M., C. McCabe, M. M. Ballard, and R. Van der Voo (1988), Magnetite authigenesis and diagenetic paleotemperatures across the northern Appalachian basin, Geology, 16, 592-595, doi:10.1130/00917613(1988)016<0592:MAADPA>2.3.CO;2.

Jackson, M., P. Rochette, G. Fillion, S. Banerjee, and J. Marvin (1993), Rock magnetism of remagnetized Paleozoic carbonates: Low-temperature behavior and susceptibility characteristics, J. Geophys. Res., 98, 6217-6225, doi:10.1029/92JB01319.

Jacobs, I. S., and C. P. Bean (1955), An approach to elongated fine particle magnets, Phys. Rev., 100, 1060-1067, doi:10.1103/PhysRev.100.1060.

Johnson, E. A., T. Murphy, and O. W. Torreson (1948), Pre-history of the Earth's magnetic field, Terr. Magn. Atmos. Electr., 53, 349-372, doi:10.1029/TE053i004p00349.

Kent, D. V., B. S. Cramer, L. Lanci, D. Wang, J. D. Wright, and R. Van der Voo (2003), A case for a comet impact trigger for the Paleocene/Eocene thermal maximum and carbon isotope excursion, Earth Planet. Sci. Lett., 211, 13-26, doi:10.1016/S0012-821X(03)00188-2.

Kind, J., A. U. Gehring, M. Winklhofer, and A. M. Hirt (2011), Combined use of magnetometry and spectroscopy for identifying magnetofossils in sediments, Geochem. Geophys. Geosyst., 12, Q08008, doi:10.1029/ 2011GC003633

King, J. W., S. K. Banerjee, and J. Marvin (1983), A new rock-magnetic approach to selecting sediments for geomagnetic paleointensity studies
Application to paleointensity for the last 4000 years, J. Geophys. Res. 88, 5911-5921, doi:10.1029/JB088iB07p05911.

Kirschvink, J. L. (1982), Paleomagnetic evidence for fossil biogenic magnetite in Western Crete, Earth Planet. Sci. Lett., 59, 388-392, doi:10.1016/0012-821X(82)90140-6.

Kissel, C., C. Laj, T. Mulder, C. Wandres, and M. Cremer (2009), The magnetic fraction: A tracer of deep water circulation in the North Atlantic, Earth Planet. Sci. Lett., 288, 444-454, doi:10.1016/j.eps1.2009.10.005.

Kok, Y. S., and L. Tauxe (1999), A relative geomagnetic paleointensity stack from Ontong-Java Plateau sediments for the Matuyama, J. Geophys. Res., 104, 25,401-25,413, doi:10.1029/1999JB900186.

Kopp, R. E., and J. L. Kirschvink (2008), The identification and biogeochemical interpretation of fossil magnetotactic bacteria, Earth Sci. Rev., 86, 42-61, doi:10.1016/j.earscirev.2007.08.001.

Kopp, R. E., B. P. Weiss, A. C. Maloof, H. Vali, C. Z. Nash, and J. L. Kirschvink (2006), Chains, clumps, and strings: Magnetofossil taphonomy with ferromagnetic resonance spectroscopy, Earth Planet. Sci. Lett. 247, 10-25, doi:10.1016/j.eps1.2006.05.001.

Kopp, R. E., T. D. Raub, D. Schumann, H. Vali, A. V. Smirnov, and J. L. Kirschvink (2007), Magnetofossil spike during the Paleocene-Eocene thermal maximum: Ferromagnetic resonance, rock magnetic, and electron microscopy evidence from Ancora, New Jersey, United States, Paleoceanography, 22, PA4103, doi:10.1029/2007PA001473.

Kruiver, P. P., M. J. Dekkers, and D. Heslop (2001), Quantification of magnetic coercivity components by the analysis of acquisition curves of isothermal remanent magnetization, Earth Planet. Sci. Lett., 189, 269-276, doi:10.1016/S0012-821X(01)00367-3.

Lanci, L., B. Delmonte, D. V. Kent, V. Maggi, P. E. Biscaye, and J. R. Petit (2012), Magnetization of polar ice: A measurement of terrestrial dust and extraterrestrial fallout, Quat. Sci. Rev., 33, 20-31, doi:10.1016/ j.quascirev.2011.11.023.

Larrasoaña, J. C., A. P. Roberts, R. J. Musgrave, E. Gràcia, E. Piñero, M. Vega, and F. Martínez-Ruiz (2007), Diagenetic formation of greigite and pyrrhotite in marine sedimentary systems containing gas hydrates, Earth Planet. Sci. Lett., 261, 350-366, doi:10.1016/j.epsl.2007.06.032.

Larrasoaña, J. C., A. P. Roberts, L. Chang, S. A. Schellenberg, J. D. Fitz Gerald, R. D. Norris, and J. C. Zachos (2012), Magnetotactic bacterial response to Antarctic dust supply during the Palaeocene-Eocene thermal maximum, Earth Planet. Sci. Lett., 333-334, 122-133, doi:10.1016/ j.eps1.2012.04.003.

Lean, C. M. B., and I. N. McCave (1998), Glacial to interglacial mineral magnetic and palaeoceanographic changes at Chatham Rise, SW Pacific Ocean, Earth Planet. Sci. Lett., 163, 247-260, doi:10.1016/ S0012-821X(98)00191-5.

Li, J., Y. Pan, G. Chen, Q. Liu, L. Tian, and W. Lin (2009), Magnetite magnetosome and fragmental chain formation of Magnetospirillum magneticum AMB-1: Transmission electron microscopy and magnetic observations, Geophys. J. Int., 177, 33-42, doi:10.1111/j.1365-246X.2009.04043.x.

Li, J. H., et al. (2010), Biomineralization, crystallography and magnetic properties of bullet-shaped magnetite magnetosomes in giant rod magnetotactic bacteria, Earth Planet. Sci. Lett., 293, 368-376.

Lippert, P. C., and J. C. Zachos (2007), A biogenic origin for anomalous fine-grained magnetic material at the Paleocene-Eocene boundary at Wilson Lake, New Jersey, Paleoceanography, 22, PA4104, doi:10.1029/ 2007PA001471.

Liu, Q. S., J. Torrent, B. A. Maher, Y. J. Yu, C. L. Deng, R. X. Zhu, and X. X. Zhao (2005), Quantifying grain size distribution of pedogenic magnetic particles in Chinese loess and its significance for pedogenesis, J. Geophys. Res., 110, B11102, doi:10.1029/2005JB003726.

Lovley, D. R. (1991), Magnetite formation during microbial dissimilatory iron reduction, in Iron Biominerals, edited by R. B. Frankel and R. P. Blakemore, pp. 151-166, Plenum, New York, doi:10.1007/978-1-46153810-3 11.

Lovley, D. R., J. F. Stolz, G. L. Nord, and E. J. P. Phillips (1987), Anaerobic production of magnetite by a dissimilatory iron-reducing microorganism, Nature, 330, 252-254, doi:10.1038/330252a0.

Maher, B. A., and R. M. Taylor (1988), Formation of ultrafine-grained magnetite in soils, Nature, 336, 368-370, doi:10.1038/336368a0.

Mastrogiacomo, G., H. Fischer, I. García-Rubio, and A. U. Gehring (2010), Ferromagnetic resonance spectroscopic response of magnetite chains in a biological matrix, J. Magn. Magn. Mater., 322, 661-663, doi:10.1016/ j.jmmm.2009.10.035.

McNeill, D. F. (1990), Biogenic magnetite from surface Holocene carbonate sediments, Great Bahama Bank, J. Geophys. Res., 95, 4363-4371, doi:10.1029/JB095iB04p04363.

Moreau, M. G., M. Ader, and R. J. Enkin (2005), The magnetization of clay-rich rocks in sedimentary basins: Low-temperature experimenta formation of magnetic carriers in natural samples, Earth Planet. Sci. Lett., 230, 193-210, doi:10.1016/j.eps1.2004.11.013. 
Moskowitz, B. M., R. B. Frankel, and D. A. Bazylinski (1993), Rock magnetic criteria for the detection of biogenic magnetite, Earth Planet. Sci. Lett., 120, 283-300, doi:10.1016/0012-821X(93)90245-5.

Muxworthy, A. R., and D. J. Dunlop (2002), First-order reversal curve (FORC) diagrams for pseudo-single domain magnetites at high temperature, Earth Planet. Sci. Lett., 203, 369-382, doi:10.1016/S0012-821X (02)00880-4.

Muxworthy, A. R., and W. Williams (2006), Critical single-domain/multidomain grain sizes in noninteracting and interacting elongated magnetite particles: Implications for magnetosomes, J. Geophys. Res., 111, B12S12, doi:10.1029/2006JB004588.

Muxworthy, A. R., and W. Williams (2009), Critical superparamagnetic/ single domain grain sizes in interacting magnetite particles: Implications for magnetosome crystals, J. R. Soc. Interface, 6, 1207-1212.

Muxworthy, A. R., W. Williams, and D. Virdee (2003), Effect of magnetostatic interactions on the hysteresis properties of single-domain and pseudo-single domain grains, J. Geophys. Res., 108(B11), 2517, doi:10.1029/2003JB002588.

Muxworthy, A. R., J. G. King, and D. Heslop (2005), Assessing the ability of first-order reversal curve (FORC) diagrams to unravel complex magnetic signals, J. Geophys. Res., 110, B01105, doi:10.1029/2004JB003195.

Néel, L. (1955), Some theoretical aspects of rock magnetism, Adv. Phys., 4, 191-243, doi:10.1080/00018735500101204.

Newell, A. J. (2005), A high-precision model of first-order reversal curve (FORC) functions for single-domain ferromagnets with uniaxial anisotropy, Geochem. Geophys. Geosyst., 6, Q05010, doi:10.1029/2004GC000877.

Otamendi, A. M., M. Díaz, V. Costanzo-Álvarez, M. Aldana, and A. Pilloud (2006), EPR stratigraphy applied to the study of two marine sedimentary sections in southwestern Venezuela, Phys. Earth Planet. Inter., 154 243-254, doi:10.1016/j.pepi.2005.04.015

Pan, Y. X., N. Petersen, M. Winklhofer, A. F. Davila, Q. S. Liu, T. Frederichs, M. Hanzlik, and R. X. Zhu (2005), Rock magnetic properties of uncultured magnetotactic bacteria, Earth Planet. Sci. Lett., 237, 311-325, doi:10.1016 j.eps1.2005.06.029.

Passier, H. F., and M. J. Dekkers (2002), Iron oxide formation in the active oxidation front above sapropel $\mathrm{S} 1$ in the eastern Mediterranean Sea as derived from low-temperature magnetism, Geophys. J. Int., 150 230-240, doi:10.1046/j.1365-246X.2002.01704.x.

Paterson, G., A. R. Muxworthy, A. P. Roberts, and C. MacNiocaill (2010), Assessment of the usefulness of lithic clasts from pyroclastic deposits for paleointensity determination, J. Geophys. Res., 115, B03104, doi:10.1029/ 2009JB006475.

Penninga, I., H. de Waard, B. M. Moskowitz, D. A. Bazylinksi, and R. B Frankel (1995), Remanence measurements on individual magnetotactic bacteria using a pulsed magnetic field, J. Magn. Magn. Mater., 149 279-286, doi:10.1016/0304-8853(95)00078-X.

Petersen, N., T. von Dobeneck, and H. Vali (1986), Fossil bacterial magnetite in deep-sea sediments from the South Atlantic Ocean, Nature, 320 611-615, doi:10.1038/320611a0.

Pike, C. R., A. P. Roberts, and K. L. Verosub (1999), Characterizing interactions in fine magnetic particle systems using first order reversal curves, J. Appl. Phys., 85, 6660-6667, doi:10.1063/1.370176.

Pike, C. R., A. P. Roberts, and K. L. Verosub (2001), First-order reversal curve diagrams and thermal relaxation effects in magnetic particles, Geophys. J. Int., 145, 721-730, doi:10.1046/j.0956-540x.2001.01419.x.

Roberts, A. P. (1995), Magnetic characteristics of sedimentary greigite $\left(\mathrm{Fe}_{3} \mathrm{~S}_{4}\right)$, Earth Planet. Sci. Lett., 134, 227-236, doi:10.1016/0012-821X (95)00131-U.

Roberts, A. P., K. L. Verosub, and R. M. Negrini (1994), Middle/Late Pleistocene relative palaeointensity of the geomagnetic field from lacustrine sediments, Lake Chewaucan, western United States, Geophys. J. Int., 118, 101-110, doi:10.1111/j.1365-246X.1994.tb04678.x.

Roberts, A. P., K. L. Verosub, R. J. Weeks, B. Lehman, and C. Laj (1995a), Mineral magnetic properties of Middle and Late Pleistocene sediments at ODP sites 883, 884, and 887, North Pacific Ocean, Proc. Ocean Drill. Program Sci. Results, 145, 483-490.

Roberts, A. P., Y. L. Cui, and K. L. Verosub (1995b), Wasp-waisted hysteresis loops: Mineral magnetic characteristics and discrimination of components in mixed magnetic systems, $J$. Geophys. Res., 100, 17,909-17,924, doi:10.1029/95JB00672.

Roberts, A. P., R. L. Reynolds, K. L. Verosub, and D. P. Adam (1996), Environmental magnetic implications of greigite $\left(\mathrm{Fe}_{3} \mathrm{~S}_{4}\right)$ formation in a 3 million year lake sediment record from Butte Valley, Northern California, Geophys. Res. Lett., 23, 2859-2862, doi:10.1029/96GL02831.

Roberts, A. P., G. S. Wilson, F. Florindo, L. Sagnotti, K. L. Verosub, and D. M. Harwood (1998), Magnetostratigraphy of lower Miocene strata from the CRP-1 core, McMurdo Sound, Ross Sea, Antarctica, Terra Antart., 5, 703-713.
Roberts, A. P., C. R. Pike, and K. L. Verosub (2000), First-order reversal curve diagrams: A new tool for characterizing the magnetic properties of natural samples, J. Geophys. Res., 105, 28,461-28,475, doi:10.1029/ 2000JB900326.

Roberts, A. P., G. S. Wilson, D. M. Harwood, and K. L. Verosub (2003), Glaciation across the Oligocene-Miocene boundary in southern McMurdo Sound, Antarctica: New chronology from the CIROS-1 drillhole, Palaeogeogr. Palaeoclimatol. Palaeoecol., 198, 113-130, doi:10.1016/S0031-0182(03)00399-7.

Roberts, A. P., Q. Liu, C. J. Rowan, L. Chang, C. Carvallo, J. Torrent, and C. S. Horng (2006), Characterization of hematite $\left(\alpha-\mathrm{Fe}_{2} \mathrm{O}_{3}\right)$, goethite $(\alpha-\mathrm{FeOOH})$, greigite $\left(\mathrm{Fe}_{3} \mathrm{~S}_{4}\right)$, and pyrrhotite $\left(\mathrm{Fe}_{7} \mathrm{~S}_{8}\right)$ using first-order reversal curve diagrams, J. Geophys. Res., 111, B12S35, doi:10.1029/ 2006JB004715.

Roberts, A. P., A. Bakrania, F. Florindo, C. J. Rowan, C. R. Fielding, and R. D. Powell (2007), High-resolution evidence for dynamic transitional geomagnetic field behaviour from a Miocene reversal, McMurdo Sound, Ross Sea, Antarctica, Earth Planets Space, 59, 815-824.

Roberts, A. P., F. Florindo, J. C. Larrasoaña, M. A. O'Regan, and X. Zhao (2010), Complex polarity pattern at the (former) Plio-Pleistocene global stratotype section at Vrica (Italy): Remagnetization by magnetic iron sulphides, Earth Planet. Sci. Lett., 292, 98-111, doi:10.1016/j.eps1.2010.01.025.

Roberts, A. P., F. Florindo, G. Villa, L. Chang, L. Jovane, S. M. Bohaty, J. C. Larrasoaña, D. Heslop, and J. D. Fitz Gerald (2011a), Magnetotactic bacterial abundance in pelagic marine environments is limited by organic carbon flux and availability of dissolved iron, Earth Planet. Sci. Lett., 310, 441-452, doi:10.1016/j.eps1.2011.08.011.

Roberts, A. P., L. Chang, C. J. Rowan, C.-S. Horng, and F. Florindo (2011b), Magnetic properties of sedimentary greigite $\left(\mathrm{Fe}_{3} \mathrm{~S}_{4}\right)$ : An update, Rev. Geophys., 49, RG1002, doi:10.1029/2010RG000336.

Robertson, D. J., and D. E. France (1994), Discrimination of remanence-carrying minerals in mixtures, using isothermal remanent magnetisation acquisition curves, Phys. Earth Planet. Inter., 82, 223-234, doi:10.1016 0031-9201(94)90074-4

Sagnotti, L., F. Florindo, K. L. Verosub, G. S. Wilson, and A. P. Roberts (1998), Environmental magnetic record of Antarctic palaeoclimate from Eocene-Oligocene glaciomarine sediments, Victoria Land margin, Geophys. J. Int , 134, 653-662, doi:10.1046/j.1365-246x.1998.00559 x.

Sagnotti, L., K. L. Verosub, A. P. Roberts, F. Florindo, and G. S. Wilson (2001), Environmental magnetic record of the Eocene-Oligocene transition in the CRP-3 drillcore, Victoria Land Basin, Antarctica, Terra Antart., 8, 507-516.

Sagnotti, L., A. P. Roberts, R. Weaver, K. L. Verosub, F. Florindo, G. S Wilson, C. R. Pike, and T. Clayton (2005), Apparent high-frequency magnetic polarity reversals due to alternating remagnetizations resulting from late diagenetic growth of greigite from siderite, Geophys. J. Int., 160, 89-100, doi:10.1111/j.1365-246X.2005.02485.x.

Sarna-Wojcicki, A. M., M. S. Pringle, and J. Wijbrans (2000), New ${ }^{40} \mathrm{Ar} /{ }^{39} \mathrm{Ar}$ age of the Bishop Tuff from multiple sites and sediment rate calibration for the Matuyama-Brunhes boundary, J. Geophys. Res., 105, 21,431-21,443

Smirnov, A. V., and J. A. Tarduno (2000), Low-temperature magnetic properties of pelagic sediments (Ocean Drilling Program Site $805 \mathrm{C}$ ): Tracers of maghemitization and magnetic mineral reduction, J. Geophys. Res. 105, 16,457-16,471, doi:10.1029/2000JB900140.

Stolz, J. F., S. B. R. Chang, and J. L. Kirschvink (1986), Magnetotactic bacteria and single-domain magnetite in hemipelagic sediments, Nature, 321, 849-851, doi:10.1038/321849a0.

Suk, D., D. R. Peacor, and R. van der Voo (1990a), Replacement of pyrite framboids by magnetite in limestone and implications for palaeomagnetism, Nature, 345, 611-613, doi:10.1038/345611a0.

Suk, D. W., R. van der Voo, and D. R. Peacor (1990b), Scanning and transmission electron-microscope observations of magnetite and other iron phases in Ordovician carbonates from east Tennessee, J. Geophys. Res., 95, 12,327-12,336, doi:10.1029/JB095iB08p12327.

Sun, D. H., J. Bloemendal, D. K. Rea, J. Vandenberghe, F. C. Jiang, Z. S An, and R. X. Su (2002), Grain-size distribution function of polymodal sediments in hydraulic and aeolian environments, and numerical partitioning of the sedimentary components, Sediment. Geol., 152, 263-277, doi:10.1016/S0037-0738(02)00082-9

Sun, Y. B., H. Y. Lu, and Z. S. An (2006), Grain size of loess, palaeosol and red clay deposits on the Chinese Loess Plateau: Significance for understanding pedogenic alteration and palaeomonsoon evolution, Palaeogeogr. Palaeoclimatol. Palaeoecol., 241, 129-138, doi:10.1016/j.palaeo. 2006.06.018.

Tarduno, J. A. (1994), Temporal trends of magnetic dissolution in the pelagic realm: Gauging paleoproductivity?, Earth Planet. Sci. Lett., 123, 39-48, doi:10.1016/0012-821X(94)90255-0. 
Tarduno, J. A., and S. Wilkison (1996), Non-steady state magnetic mineral reduction, chemical lock-in, and delayed remanence acquisition in pelagic sediments, Earth Planet. Sci. Lett., 144, 315-326, doi:10.1016/ S0012-821X(96)00174-4

Tarduno, J. A., W. L. Tian, and S. Wilkison (1998), Biogeochemical remanent magnetization in pelagic sediments of the western equatorial Pacific Ocean, Geophys. Res. Lett., 25, 3987-3990, doi:10.1029/1998GL900079.

Tauxe, L. (1993), Sedimentary records of relative paleointensity of the geomagnetic field: Theory and practice, Rev. Geophys., 31, 319-354, doi:10.1029/93RG01771.

Tauxe, L., and P. Hartl (1997), 11 million years of Oligocene geomagnetic field behaviour, Geophys. J. Int., 128, 217-229, doi:10.1111/j.1365246X.1997.tb04082.x.

Tauxe, L., and N. J. Shackleton (1994), Relative palaeointensity records from the Ontong-Java Plateau, Geophys. J. Int., 117, 769-782, doi:10.1111/ j.1365-246X.1994.tb02469.x.

Tauxe, L., and G. Wu (1990), Normalized remanence in sediments of the western equatorial Pacific: Relative paleointensity of the geomagnetic field? J. Geophys. Res., 95, 12,337-12,350, doi:10.1029/JB095iB08p12337.

Tauxe, L., and T. Yamazaki (2007), Paleointensities, in Treatise on Geophysics, vol. 5, edited by M. Kono, pp. 509-563, Elsevier, New York, doi:10.1016/B978-044452748-6.00098-5.

Tauxe, L., T. A. T. Mullender, and T. Pick (1996), Potbellies, wasp-waists, and superparamagnetism in magnetic hysteresis, J. Geophys. Res., 101, 571-583, doi:10.1029/95JB03041.

Thompson, R. S., C. G. Oviatt, A. P. Roberts, J. Buchner, R. Kelsey, C. Bracht, R. M. Forester, and J. P. Bradbury (1995), Sedimentology, paleontology, and paleomagnetism of Pliocene-Early Pleistocene lacustrine deposits in two cores from western Utah, U.S. Geol. Surv. Open File Rep., 95-1, 94 pp.

Torii, M. (1997), Low-temperature oxidation and subsequent downcore dissolution of magnetite in deep-sea sediments, ODP Leg 161 (western Mediterranean), J. Geomagn. Geoelectr., 49, 1233-1245, doi:10.5636/ jgg.49.1233.

Valet, J.-P., and L. Meynadier (1993), Geomagnetic field intensity and reversals during the past four million years, Nature, 366, 234-238, doi: $10.1038 / 366234 \mathrm{a} 0$.

Vali, H., O. Förster, G. Amarantidis, and N. Petersen (1987), Magnetotactic bacteria and their magnetofossils in sediments, Earth Planet. Sci. Lett. 86, 389-400, doi:10.1016/0012-821X(87)90235-4.

Verosub, K. L., F. Florindo, L. Sagnotti, A. P. Roberts, and G. S. Wilson (2000), Environmental magnetism of Oligocene-Miocene glaciomarine strata from the CRP-2/2A core, McMurdo Sound, Ross Sea, Antarctica, Terra Antart., 7, 599-608.

Weaver, R., A. P. Roberts, and A. J. Barker (2002), A late diagenetic (synfolding) magnetization carried by pyrrhotite: Implications for paleomagnetic studies from magnetic iron sulphide-bearing sediments, Earth Planet. Sci. Lett., 200, 371-386, doi:10.1016/S0012-821X(02)00652-0.

Weiss, B. P. S. S. Kim, J. L. Kirschvink, R. E. Kopp, M. Sankaran, A. Kobayashi, and A. Komeili (2004), Ferromagnetic resonance and lowtemperature magnetic test for biogenic magnetite, Earth Planet. Sci. Lett., 224, 73-89, doi:10.1016/j.eps1.2004.04.024.

Weltje, G. J., and M. A. Prins (2003), Muddled or mixed? Inferring palaeoclimate from size distributions of deep-sea clastics, Sediment. Geol., 162 , 39-62, doi:10.1016/S0037-0738(03)00235-5.

Wilson, G. S., F. Florindo, L. Sagnotti, K. L. Verosub, and A. P. Roberts (2000), Magnetostratigraphy of Oligocene-Miocene glaciomarine strata from the CRP-2/2A core, McMurdo Sound, Ross Sea, Antarctica, Terra Antart., 7, 631-646.

Yamazaki, T. (2008), Magnetostatic interactions in deep-sea sediments inferred from first-order reversal curve diagrams: Implications for relative paleointensity normalization, Geochem. Geophys. Geosyst., 9, Q02005, doi:10.1029/2007GC001797.

Yamazaki, T. (2009), Environmental magnetism of Pleistocene sediments in the North Pacific and Ontong-Java Plateau: Temporal variations of detrital and biogenic components, Geochem. Geophys. Geosyst., 10, Q07Z04, doi:10.1029/2009GC002413.

Yamazaki, T. (2012), Paleoposition of the Intertropical Convergence Zone in the eastern Pacific inferred from glacial-interglacial changes in terrigenous and biogenic magnetic mineral fractions, Geology, 40, 151-154, doi:10.1130/G32646.1.

Yamazaki, T., and H. Kawahata (1998), Organic carbon flux controls the morphology of magnetofossils in sediments, Geology, 26, 1064-1066, doi:10.1130/0091-7613(1998)026<1064:OCFCTM >2.3.CO;2.

Yamazaki, T., and H. Oda (2005), A geomagnetic paleointensity stack between 0.8 and 3.0 Ma from equatorial Pacific sediment cores, Geochem. Geophys. Geosyst., 6, Q11H20, doi:10.1029/2005GC001001.

Yamazaki, T., and P. Solheid (2011), Maghemite-to-magnetite reduction across the Fe-redox boundary in a sediment core from the Ontong-Java Plateau: Influence on relative palaeointensity estimation and environmental magnetic application, Geophys. J. Int., 185, 1243-1254, doi:10.1111/ j.1365-246X.2011.05021.x

Zhou, L. P., F. Oldfield, A. G. Wintle, S. G. Robinson, and J. T. Wang (1990), Partly pedogenic origin of magnetic variations in Chinese loess, Nature, 346, 737-739, doi:10.1038/346737a0. 